\title{
Biomarkers in preclinical cancer imaging
}

\author{
Monique R. Bernsen • Klazina Kooiman • \\ Marcel Segbers • Fijs W. B. van Leeuwen • \\ Marion de Jong
}

Received: 31 October 2014 / Accepted: 16 December 2014 / Published online: 12 February 2015

(C) The Author(s) 2015. This article is published with open access at Springerlink.com

\begin{abstract}
In view of the trend towards personalized treatment strategies for (cancer) patients, there is an increasing need to noninvasively determine individual patient characteristics. Such information enables physicians to administer to patients accurate therapy with appropriate timing. For the noninvasive visualization of disease-related features, imaging biomarkers are expected to play a crucial role. Next to the chemical development of imaging probes, this requires preclinical studies in animal tumour models. These studies provide proof-ofconcept of imaging biomarkers and help determine the pharmacokinetics and target specificity of relevant imaging probes, features that provide the fundamentals for translation to the clinic. In this review we describe biological processes derived from the "hallmarks of cancer" that may serve as imaging biomarkers for diagnostic, prognostic and treatment response monitoring that are currently being studied in the preclinical setting. A number of these biomarkers are also being used for the initial preclinical assessment of new intervention strategies. Uniquely, noninvasive imaging approaches allow longitudinal assessment of changes in biological processes, providing information on the safety, pharmacokinetic
\end{abstract}

M. R. Bernsen $(\bowtie) \cdot$ M. Segbers $\cdot$ M. de Jong

Department of Nuclear Medicine, Erasmus MC Rotterdam, PO Box

2040, 3000 CA Rotterdam, The Netherlands

e-mail: m.bernsen@erasmusmc.nl

M. R. Bernsen • M. de Jong

Department of Radiology, Erasmus MC Rotterdam,

Rotterdam, The Netherlands

K. Kooiman

Department of Biomedical Engineering, Thorax Center, Erasmus

MC Rotterdam, Rotterdam, The Netherlands

F. W. B. van Leeuwen

Interventional Molecular Imaging Laboratory, Department of

Radiology, Leiden University Medical Center,

Leiden, The Netherlands profiles and target specificity of new drugs, and on the antitumour effectiveness of therapeutic interventions. Preclinical biomarker imaging can help guide translation to optimize clinical biomarker imaging and personalize (combination) therapies.

Keywords Preclinical · Biomarker · Imaging · Molecular imaging $\cdot$ Cancer $\cdot$ Multimodality $\cdot$ Hallmarks

\section{Introduction}

In connection with the increasing trend towards personalized medicine, the development of imaging biomarkers and quantitative imaging techniques has been identified as a major research priority in medical imaging communities [1-4]. Adhering to the definition of a biomarker proposed by the Biomarkers Definitions Working Group [5], an imaging biomarker is: "A characteristic that can be objectively measured from imaging data as an indicator of normal biological processes, pathogenic processes, or pharmacological responses to a therapeutic intervention". In the clinical as well as the preclinical research setting, imaging biomarkers can be a measure of anatomical, physiological/functional or molecular characteristics (Table 1). Anatomical and functional imaging biomarkers, such as imaging-based tumour size measurements and tumour perfusion measurements, are routinely used in clinical studies, but are less commonly used in preclinical studies, and vice versa, the use of molecular imaging biomarkers is more common in preclinical studies. The latter often require the use of new chemical entities that require preclinical evaluation before they become safely applicable in humans [6].

Preclinical studies are very important to obtain more insight into and a better understanding of biological and 
Table 1 Examples of typical imaging biomarkers

\begin{tabular}{llll}
\hline Type & Characteristic & Imaging method & References \\
\hline Anatomical & Tumour size/morphology & MRI, CT, US & {$[157]$} \\
Physiological/functional & Vessel density & CE MRI, CE CT, CE US & {$[205,206]$} \\
& Vessel functionality & CE MRI, CE CT, CE US & {$[206-207]$} \\
& Cellular integrity & DW MRI & {$[185]$} \\
Molecular & Metabolic activity/metabolites & FDG PET/MRS & {$[209-210]$} \\
& Receptor expression & PET, SPECT, USMI, optical & {$[74,118,119,125,128,130,195]$} \\
& Enzymatic activity & PET, SPECT, MRI, optical & {$[18,175,177,179]$} \\
\hline
\end{tabular}

MRI magnetic resonance imaging, $C T$ computed tomography, US ultrasonography, PET positron emission tomography, $C E$ contrast-enhanced, $D W$ diffusion-weighted, FDG fluoro-D-glucose, MRS magnetic resonance spectroscopy, USMI ultrasound molecular imaging

pathological processes and to perform initial assessments of the therapeutic potential of newly developed drugs. Classically, such studies have been performed using large groups of animals and killing them at various time-points followed by histopathological examination of harvested tissue. With the current availability of high-resolution and highly sensitive preclinical imaging technologies many biological and pathological tissue characteristics can now be noninvasively and longitudinally assessed in living animals (Table 2). Not only does this allow reduced animal use, but it also provides more accurate information compared to the classical technologies $[7,8]$. With the availability of animal imaging systems similar to clinical imaging systems, preclinical studies offer valuable options in providing proof-of-concept in the development process of new imaging biomarkers for clinical use.

Next to imaging systems, imaging agents are of crucial importance in biomedical imaging. Most commonly they are contrast agents and tracers that show accumulation at the target site after binding to receptor structures. Alternatively, specific enzymatic cleavage mechanisms may be exploited. Examples include: radiotracers, fluorescent molecules, paramagnetic ions or combinations thereof [9-18]. Small particles, including nanoparticles, liposomes and microbubbles, that can be (non)covalently bound to targeting molecules have also been developed [17, 19-23]. Such vectors are promising in the area of drug delivery and MRI, optical and photoacoustic imaging, contrast-enhanced ultrasonography and ultrasound molecular imaging, and thermoablative therapy $[17,19$, 23-25]. Examples include ligand-functionalized polymershelled microcapsules [26] and mixed liposome/peptide/ DNA (LPD) nanocomplexes [27] for nuclear and optical imaging as well as for MRI, illustrating the versatile potential of targeted and differentially labelled particles as research tools in cancer imaging.

In cancer research, the search for and use of imaging biomarkers has been strongly connected with the "hallmarks of cancer" defined in the past two decades (Fig. 1) [28, 29]. These hallmarks are considered crucial characteristics of tumours that define their level of malignancy and/or responsiveness for treatment. As such these characteristics can be considered indicative of a patient's prognosis. Impressive developments in the areas of imaging technology and imaging tracers have strengthened preclinical imaging studies on the hallmarks of cancer. Following these hallmarks, in this review we describe the state of the art and future perspectives of imaging biomarkers in preclinical in vivo oncological studies,

Table 2 Overview of common in vivo small-animal imaging modalities

\begin{tabular}{|c|c|c|c|c|c|c|c|}
\hline Technology & $\begin{array}{l}\text { Means of } \\
\text { detection }\end{array}$ & Resolution & Depth & Quantitative & Agents & Target & Relative cost \\
\hline $\mathrm{CT}$ & $\begin{array}{l}\text { Ionizing radiation } \\
\text { (X-rays) }\end{array}$ & $50 \mu \mathrm{m}$ & No limit & Yes & Iodinated molecules & $\begin{array}{l}\text { Anatomical, } \\
\text { physiological }\end{array}$ & $€ €$ \\
\hline PET & $\begin{array}{l}\text { Ionizing radiation } \\
\quad(\gamma \text {-rays })\end{array}$ & $1-2 \mathrm{~mm}$ & No limit & Yes & $\begin{array}{l}{ }^{19} \mathrm{~F}-,{ }^{64} \mathrm{Cu}-,{ }^{68} \mathrm{Ga}-\text {, or }{ }^{11} \\
\text { C-labelled compounds }\end{array}$ & $\begin{array}{l}\text { Physiological, } \\
\text { molecular }\end{array}$ & $€ €$ \\
\hline SPECT & $\begin{array}{l}\text { Ionizing radiation } \\
\quad(\gamma \text {-rays }\end{array}$ & $0.3-1 \mathrm{~mm}$ & No limit & Yes & $\begin{array}{l}{ }^{99 \mathrm{~m}} \mathrm{Tc}-,,{ }^{111} \mathrm{In}-,{ }^{67} \mathrm{Ga}-\text { labelled } \\
\text { compounds }\end{array}$ & $\begin{array}{l}\text { Physiological, } \\
\text { molecular }\end{array}$ & $€ €$ \\
\hline MRI & Electromagnetism & $10-100 \mu \mathrm{m}$ & No limit & Yes & $\begin{array}{l}\text { Paramagnetic and magnetic } \\
\text { compounds (iron oxide; } \\
\text { chelated } \mathrm{Gd}^{3+} \text { ) }\end{array}$ & $\begin{array}{l}\text { Anatomical, } \\
\text { physiological }\end{array}$ & $€ € €$ \\
\hline US & Acoustic waves & $50 \mu \mathrm{m}$ & Centimetres & Yes & Microbubbles & Anatomical & $€$ \\
\hline Optical & Light & $1-5 \mathrm{~mm}$ & $<3 \mathrm{~cm}$ & Yes & Luciferine, fluorochromes & $\begin{array}{l}\text { Physiological, } \\
\text { molecular }\end{array}$ & $€$ \\
\hline
\end{tabular}

Adapted from: de Jong et al. [8] 


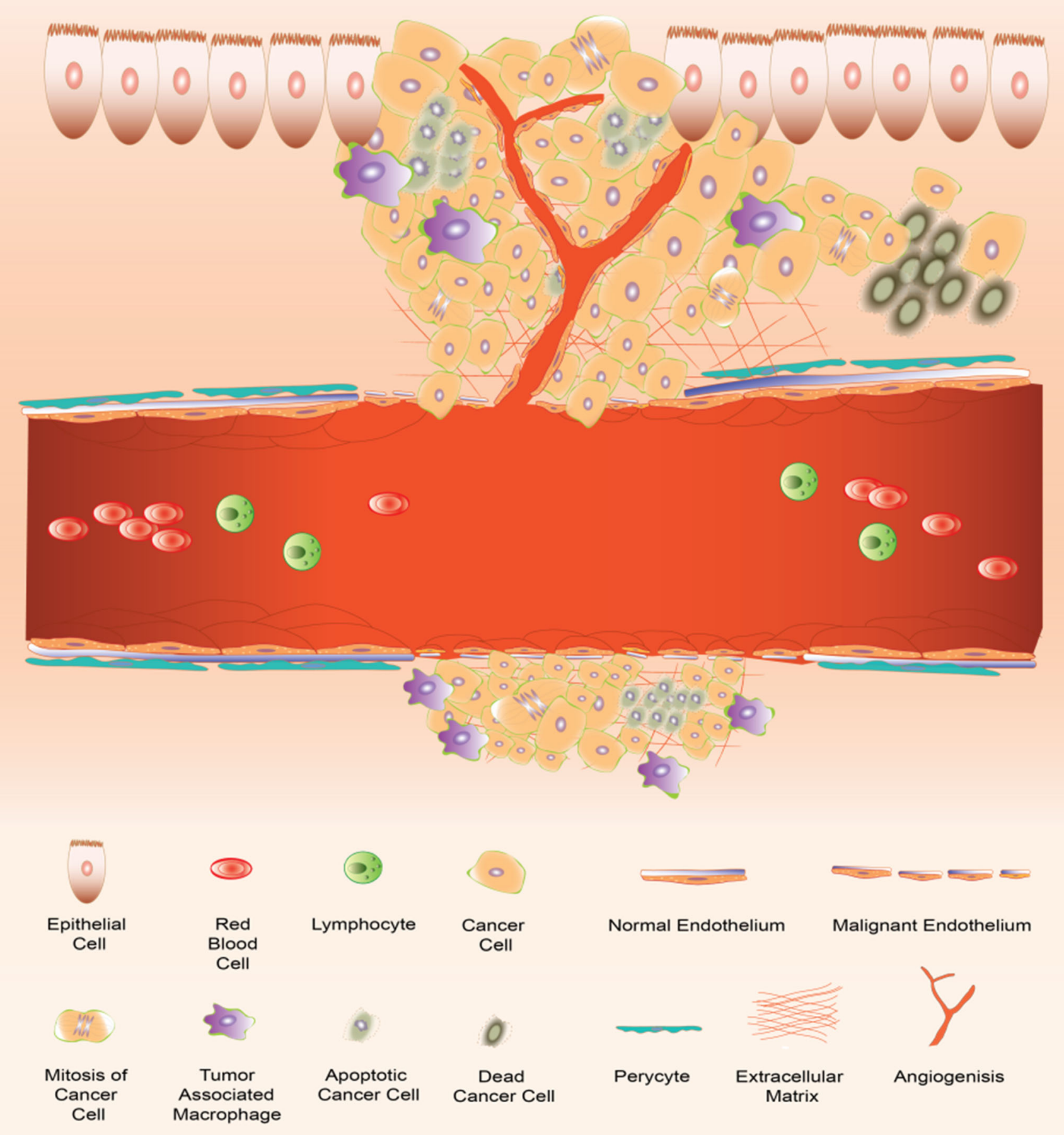

Fig. 1 Hallmarks of cancer and imaging biomarkers ( 1 uncontrolled proliferation, 2 angiogenesis, 3 altered metabolism, 4 invasion and metastasis, 5 inflammation and immune cells, 6 cell death)

as well as recent successful translation into the clinic. We also address specific challenges encountered in preclinical research regarding the influence of animal handling techniques on research findings. Due to the focus on hallmarks and due to space constraints, we were not able to cover fully the extensive field of tumour imaging using tumour-specific markers, for example somatostatin receptors (SSTR), epidermal growth factor receptors (EGFR) and oestrogen receptors. Many of these markers are addressed in more detail in other, more clinically oriented, chapters of this special issue, and 
have also been discussed in various recent excellent reviews [30-33], to which the reader is referred to.

\section{Imaging biomarkers for the "hallmarks of cancer"}

\section{Imaging proliferation/growth}

Rapid and uncontrolled proliferation is the primary hallmark of cancer and underlies various other characteristics of tumours, e.g. angiogenesis and altered metabolic profiles [34]. High proliferative activity is often linked to tumour aggressiveness and is therefore considered a biomarker suitable for prognosis [35]. Furthermore, in radiotherapy-based treatment strategies the proliferative index of tumours is further considered a predictive biomarker of response. Reduction in proliferative activity in tumours, on the other hand, may function as a biomarker for therapeutic response assessment, especially with treatment strategies that have a primarily cytostatic effect. Consequently, significant effort has been dedicated to the development and validation of imaging biomarkers for tumour cell proliferation. Nuclear imaging techniques based on probing the so-called thymide salvage pathway, using tracers such as ${ }^{11} \mathrm{C}$-FMAU, ${ }^{18} \mathrm{~F}$-FLT, and ${ }^{76} \mathrm{Br}$-BFU, are well-known examples for proliferation imaging [36]. In both preclinical [36] and clinical $[35,37]$ studies significant correlations have been found between uptake of these tracers and proliferative activity determined in tissue biopsies ex vivo. These tracers are still under investigation for their use as imaging biomarkers for early treatment response assessment. In various preclinical studies major decreases in ${ }^{18} \mathrm{~F}$-FLT uptake were observed following antitumour treatment [38-41]. In these studies decrease in ${ }^{18} \mathrm{~F}$-FLT uptake also coincided with reduced proliferative activity or reduced tumour growth. However, despite the fact that similar observations were made in clinical studies, various limitations of these techniques have also been identified, including incorporation into mitochondrial DNA instead of nuclear DNA and high uptake in liver and bone marrow. These characteristics limit the specificity of these tracers for actual tumour cell proliferation. For FLT, a specific limitation is the fact that ${ }^{18} \mathrm{~F}-\mathrm{FLT}$ is not incorporated into DNA at all, but is only trapped in the cytosol [42]. FLT uptake is in that sense not directly related to DNA synthesis. This may be a main reason why in various forms of cancer no relationship between

${ }^{18} \mathrm{~F}$-FLT uptake and proliferative index or response to treatment has been found $[35,43,44]$. Because of the encountered limitations of these thymidine analogues alternative approaches for cell proliferation imaging have been explored. Recent efforts in this respect include probing of type II topoisomerase (Topo-II) activity and expression levels of the sigma-2 receptor.

Topo-II is an ATP-dependent enzyme that is involved in cell cycle control and is essential in transcription, replication and chromosome segregation processes, and shows overexpression of one of its isoforms (Topo-II $\alpha$ ) in various types of cancer [45-47]. Next to being an attractive target for molecular therapy, Topo-II is therefore also considered an attractive target for imaging cell proliferation [45-48]. Some recent preclinical studies have shown the basic feasibility of generating imaging probes for Topo-II $\alpha$. Further development and optimization of these probes is required though, since the tracers generated to date show unfavourable biodistribution in vivo $[48,49]$.

Another recently proposed target that may be suitable as an imaging marker of cell proliferation is the sigma-2 receptor. Sigma receptors are upregulated in rapidly proliferating cells, with the sigma- 2 receptor being specifically overexpressed in proliferating tumour cells, i.e. tenfold compared to quiescent tumour cells [50]. Because of this specificity of sigma-2 receptor expression in actual proliferating tumour cells, it offers unique options in tumour imaging. Current efforts are therefore dedicated to the development of suitable imaging probes for the sigma-2 receptor [51-53]. A promising tracer in this respect is $\left[{ }^{18} \mathrm{~F}\right] \mathrm{ISO}-1$. Uptake of this tracer has been shown to be significantly correlated with Ki-67 expression in animal models [54, 55], as well as in a first in-patient study [56]. In a recent preclinical imaging study, Shoghi et al. [57] evaluated the usefulness of this tracer in the measurement of the proliferative status of tumours and as a marker of early response. In two breast cancer xenograft models, they observed significant correlations between tumour uptake of the radiolabelled ligands and growth and proliferative status of the tumours (Fig. 2).

In conclusion, currently no validated imaging probe for the noninvasive assessment of the proliferative status of tumours exists. Recent preclinical studies have identified some potential relevant targets and generation and evaluation of probes specific for these targets are underway.

\section{Imaging tumour angiogenesis}

Since angiogenesis is a critical process related to tumour growth and metastasis, a vast amount of effort has been put into the development and validation of imaging techniques for visualization and quantification of vessel density and vascular functionality, using (dynamic) contrast-enhanced imaging techniques. Angiogenesis is an imaging biomarker applied in tumour diagnosis and in the prediction and assessment of treatment response [58-60]. In recent years these techniques have also been increasingly used in the preclinical cancer research setting, including studies regarding the assessment of novel antiangiogenic treatment strategies, drug delivery studies and tumour model validation [61-63]. However, given the lack of standardization of these techniques and uncertainty in the interpretation of the derived parameters, which also holds true in the clinical setting, preclinical studies are also focused 

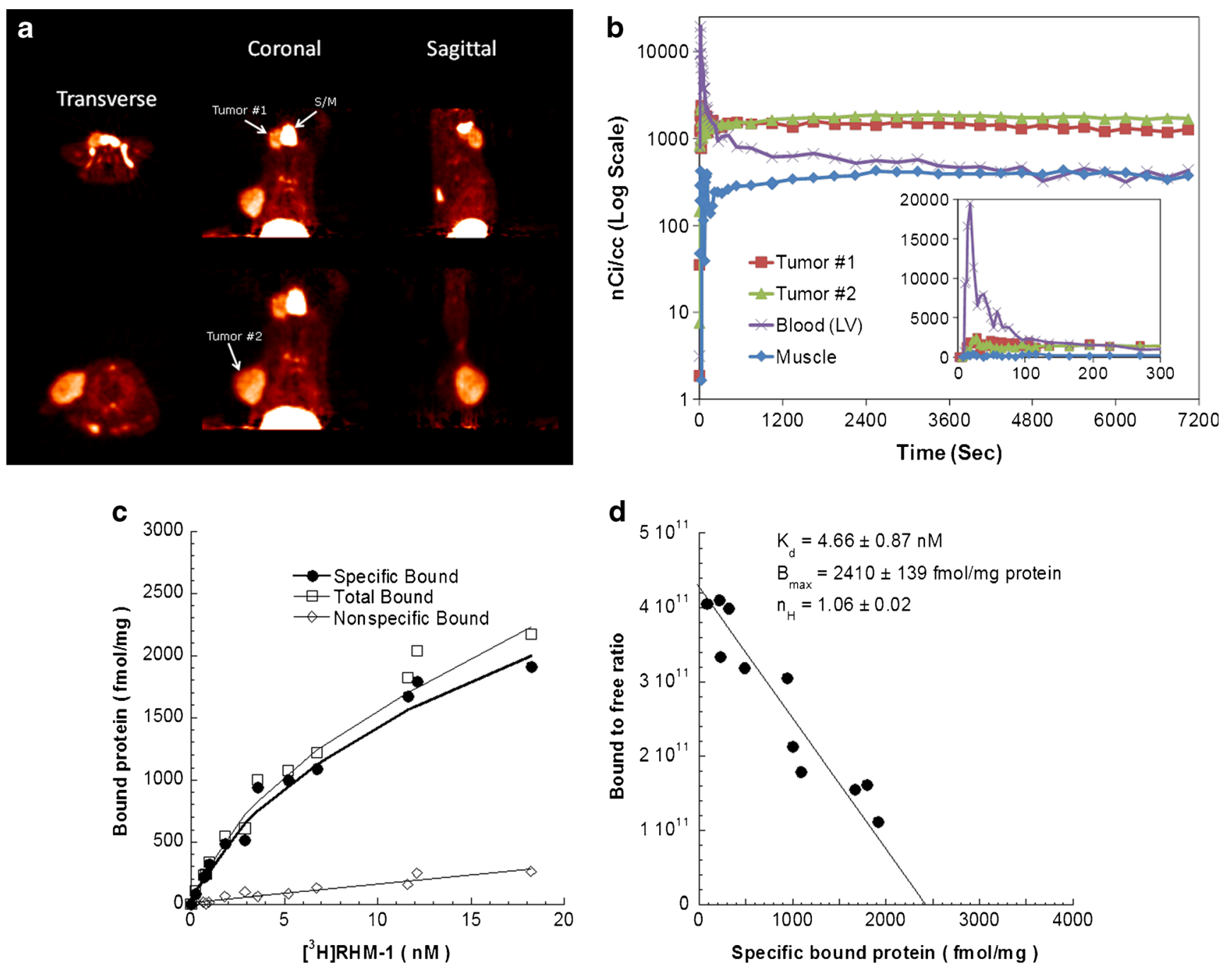

Fig. 2 Characterization of the pharmacokinetics of $\left[{ }^{18} \mathrm{~F}\right] \mathrm{ISO}-1$ and in vitro determination of sigma-2 receptor density in a rat model of mammary tumour induced by injection of $N$-methyl- $N$-nitrosourea. a Twohour summed images show two tumours and the submandibular gland $(S / M)$. The liver is evident in the coronal slices. b Time-activity curves of the two tumours, muscle and the left ventricular blood pool (inset shows

on defining the technological aspects of these techniques [64-66].

In the era of molecular medicine, molecular imaging approaches in general, including techniques for the assessment of angiogenesis and angiogenic processes, have been receiving increasing attention. So with the elucidation of molecular processes in angiogenesis, various imaging targets have been identified and are under investigation (Table 3). Often these involve membrane proteins expressed by endothelial cells, but proteins involved in angiogenesis and expressed by tumour cells or stromal cells are also targets of interest. Two of the most interesting targets in this respect are carbonic anhydrase IX [67, 68] and hypoxia-inducible factor-1 [69]. In many cases these targets are not only considered as imaging targets, but also as targets for treatment [70-72]. A variety of imaging

the kinetics during the initial $5 \mathrm{~min}$ ). $\mathbf{c}$ Representative saturation binding experiments which show the total bound, nonspecific bound and specific bound $\left[{ }^{18} \mathrm{~F}\right] \mathrm{ISO}-1$. d Representative Scatchard plots which were used to determine the equilibrium dissociation constant $\left(K_{\mathrm{d}}\right)$, the maximum number of binding sites $\left(B_{\max }\right)$ and the Hill coefficient $\left(n_{\mathrm{H}}\right)$. Reprinted from Shoghi et al. [57]

methods, including PET, SPECT, MRI, ultrasonography and optical imaging, have been used in molecular imaging strategies.

A technique that has recently been gaining a lot of ground in these applications is ultrasound molecular imaging using targeted microbubbles (Fig. 3) [25, 73, 74]. In genetically modified mouse models, VEGFR2-targeted microbubbles have been shown to detect precancerous tissue, such as liver dysplasia [75] and breast hyperplasia. Ultrasound molecular imaging has also shown potential as an early response marker in several cancer types [76-79]. In recent studies the superiority of ultrasound molecular imaging over functional vascular imaging and tumour size measurements for response monitoring has been demonstrated in selected tumour models [80, 81]. This technique is now on its way to the clinic; a recent 


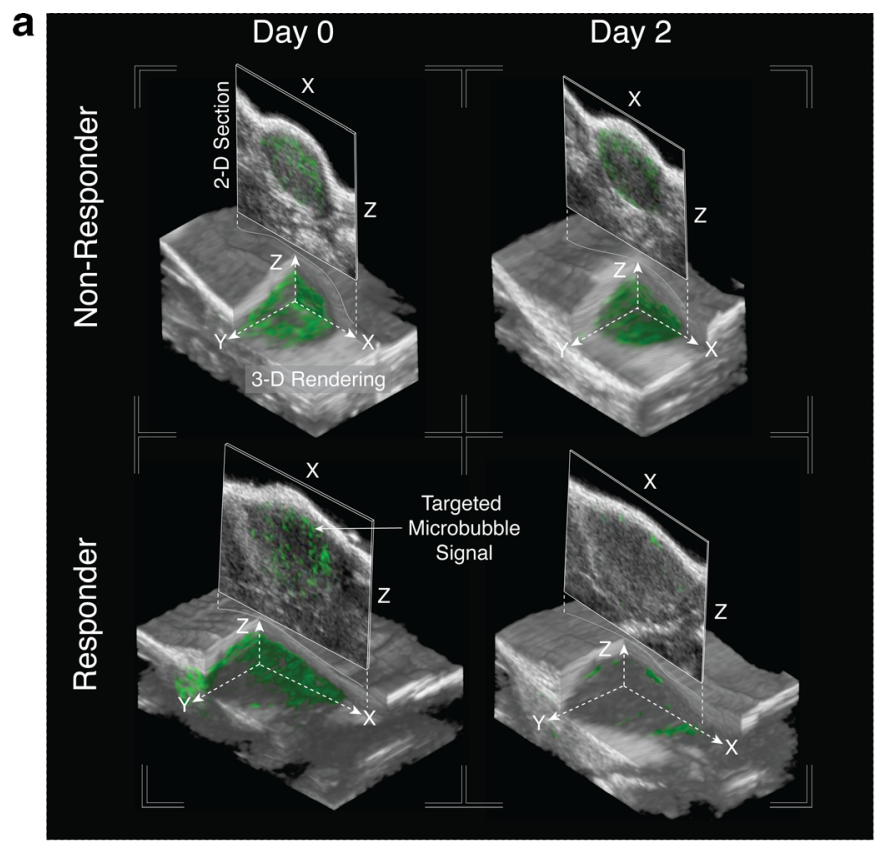

b

Thy1-positive Tumor

Thy1-negative Control Tumor
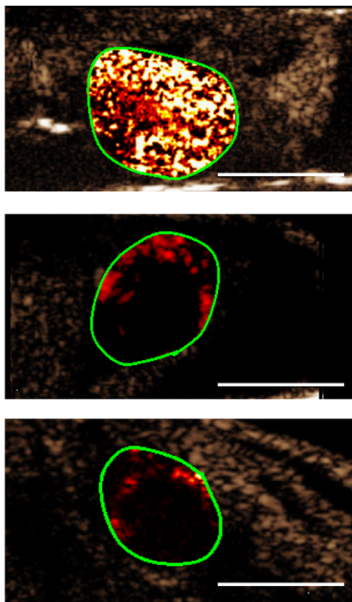

Fig. 3 Ultrasound molecular imaging of tumour angiogenesis. a 3D images of a nonresponding (top) and a responding (bottom) pancreatic tumour in mice on day 0 and day 2 after aurora A kinase inhibitor treatment. The green colour represents the signal from the $\alpha_{v} \beta_{3^{-}}$ targeted microbubbles which is overlain on the black and white B-mode ultrasound image. $\mathbf{b}$ The group of Willmann has overcome the problem of poor expression of human cancer-specific endothelial markers in murine models by developing a mouse model that expresses human vascular biomarkers. They transfected mouse endothelial cells with the human biomarker of interest and implanted these with the tumour cells of interest. Using this method, Foygel et al. [232] expressed human thymocyte

phase 0 clinical trial demonstrated that VEGFR2-targeted microbubbles can be successfully used for prostate cancer imaging [82] and to have the potential for monitoring patients at high risk of cancer, such as aggressive primary hepatocellular carcinoma [83]. In the preclinical setting new developments in this field involve the use of 3D imaging techniques
$\mathrm{MB}_{\text {Control }}$
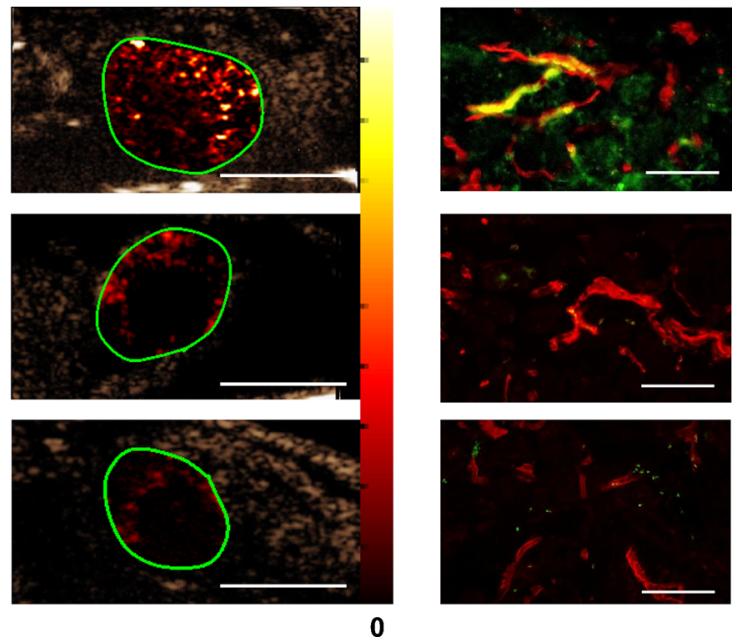

differentiation antigen 1 (Thy 1 or CD90) in pancreatic ductal adenocarcinoma. Left The Thy1-targeted microbubble ( $\left.\mathrm{MB}_{\text {Thy1 }}\right)$ signal (colourcoded scale in arbitrary units) overlain on black and white B-mode ultrasound images is strong in Thyl-positive tumour, whilst there is only background signal in both types of control tumour. Centre There is also low signal from control-targeted microbubbles $\left(\mathrm{MB}_{\mathrm{Control}}\right.$; green circles tumour regions). Right Corresponding immunofluorescence micrographs (ex vivo) of merged double-stained sections (red murine CD31, green human Thy1), confirming human Thy1 expression on neovasculature in Thy1-positive tumours (yellow). Scale bars: $5 \mathrm{~mm}$ (left and centre), $50 \mu \mathrm{m}($ right $)$. Reprinted from Tsurata et al. [233]

and microbubbles functionalized with ligands specific for tumour-specific markers (Fig. 3).

Additional molecular imaging strategies regarding the use of imaging biomarkers for the assessment of tumour angiogenesis involve imaging approaches to assess tissue hypoxia, a physiological effect strongly linked to the aberrant tissue 
Table 3 Selected examples of molecular targets as imaging biomarkers of angiogenesis

\begin{tabular}{lll}
\hline Target & Preclinical/Clinical use & References \\
\hline Integrins & Clinical, preclinical & {$[73,212-219]$} \\
VEGFR2 & Clinical, preclinical & {$[76,220-222]$} \\
VEGF & Preclinical & {$[223,224]$} \\
Tumour endothelial & Preclinical & {$[225,226]$} \\
$\quad$ marker 8 (TEM8) & & \\
CD147 & Preclinical & {$[227-229]$} \\
CD276 & Preclinical & {$[230]$} \\
EGFR & Preclinical & {$[227,231]$} \\
\hline
\end{tabular}

vasculature in many tumours [84]. Tumour oxygenation can be imaged by optical techniques [85, 86], MRI [67, 87-89], photoacoustic techniques [90] and nuclear techniques [91, 92]. These approaches are in most cases based on the detection of haemoglobin saturation using techniques such as BOLD MRI, or accumulation of tracers following a reduction reaction by which the reduced molecule becomes entrapped or bound within tumour cells or tissue, for example with nitroimidazole-based probes.

In view of current antiangiogenic treatment strategies molecular imaging of angiogenic processes is very much in focus. At the preclinical level various targets have been identified and are currently being evaluated. A number of these have also entered clinical testing, but data obtained so far have not resulted in consistent and conclusive results, and more studies are warranted.

\section{Imaging cellular energetics}

Rapid cell growth and hypoxic conditions are considered driving forces behind altered energy metabolism, as is often found in tumours. However, oncogenetically driven processes have also been described as underlying causes of altered energy metabolism. In tumours, specifically the high degree of reliance on glucose as the metabolic substrate and the so-called Warburg effect provide a basis for metabolism imaging. The Warburg effect entails the phenomenon of aerobic glycolysis, where even under normoxic conditions tumour cells convert glucose into lactate. The preferred use of glucose as substrate in many tumour types is the reason for the avid uptake of fluorodeoxyglucose (FDG) and the reason for the high clinical value of ${ }^{18} \mathrm{~F}-\mathrm{FDG}$ in cancer diagnostics and treatment response monitoring. The use of FDG as imaging biomarker for tumour localization, prognosis and response has been addressed in various excellent clinical reviews to which the reader is referred to [93-95].

Because some limitations in the use of ${ }^{18}$ F-FDG PET have also been recognized, e.g. accumulation in non-tumour tissue and limited uptake in slow-growing tumours such as prostate cancer and neuroendocrine tumours, alternative methods for metabolic profiling are also under investigation. Since tumours may also display changes in protein and phospholipid metabolism, these processes also provide imaging targets [96-98]. New insights into the role of amino acids and amino acid transporters have instigated the development and evaluation of new radiolabelled amino acids, as recently reviewed by Huang and McConathy [96]. Findings of altered phospholipid metabolism have resulted in the development and testing of radiolabelled choline analogues [99, 100]. Schwarzenbock et al. [101] recently addressed the issue of sensitivity and specificity of three such tracers in a xenograft prostate cancer model in mice. They found that the new tracer $\left[{ }^{11} \mathrm{C}\right] \mathrm{SMC}$ performs better than the clinically used $\left[{ }^{11} \mathrm{C}\right] \mathrm{CHO}$. Emonds et al. on the other hand reported a potential limitation of choline-based tracers [102]. Comparing $\left[{ }^{11} \mathrm{C}\right] \mathrm{CHO}$ and $\left[{ }^{11} \mathrm{C}\right]$ acetate in androgen-dependent and androgen-independent prostate cancer xenograft models, they found that androgen deprivation influences the uptake of $\left[{ }^{11} \mathrm{C}\right] \mathrm{CHO}$, and warned of the risk of underestimation of the presence of recurrent prostate cancer following androgen deprivation therapy.

Magnetic resonance spectroscopy (MRS) has played a major role in metabolic profiling of tumours for several decades [103]. However, due to issues regarding sensitivity and the need for specialized techniques, MRS has not yet evolved as a routine clinical practice. Nonetheless, MRS approaches continue to be explored for certain types of cancer [104] with recent increasing interest in its use in prostate cancer [105, 106] and breast cancer [107, 108]. The interest in MRSbased assessment of tumour metabolism has recently undergone a further boost by the newly developed technique of hyperpolarized MRI [109]. This technique is based on MRS imaging of ${ }^{13} \mathrm{C}$-labelled cell substrates that have undergone dynamic nuclear polarization (or hyperpolarization). The hyperpolarization step has the big advantage of enhancing the sensitivity of detection of ${ }^{13} \mathrm{C}$-labelled compounds by more than 10,000-fold [110], by which one of the main limitations of ${ }^{13} \mathrm{C}$-MRS can be overcome, thus allowing sensitive assessment of the dynamics of metabolic processes in vivo. This technique has opened up new possibilities in studying metabolic pathways in tumours by which a better understanding of the sometimes controversial metabolic signatures in tumours can be obtained [111]. Also, the potential use of this technique for response assessment in cancer therapy was recently demonstrated. Rodrigues et al. found highly tumour-specific conversion of hyperpolarized $\left[\mathrm{U}-{ }^{2} \mathrm{H}, \mathrm{U}-{ }^{13} \mathrm{C}\right]$ glucose to lactate and a marked decrease in the lactate/glucose ratio $24 \mathrm{~h}$ after treatment with the chemotherapeutic drug etoposide in murine tumour models of lymphoma and lung tumours (Fig. 4) [112]. In prostate cancer cell lines, Canapè et al. [113] demonstrated the ability of hyperpolarized NMR, using $\left[5-{ }^{13} \mathrm{C}\right]$ glutamine as a probe, to noninvasively assess glutaminolysis. They were also able to show that the rate of 
Fig. $4{ }^{13} \mathrm{C}$ spectroscopic imaging showing the spatial distribution of labelled glucose and lactate in EL4 and LL2 tumour-bearing mice. a Representative ${ }^{13} \mathrm{C}$ MR spectra acquired from subcutaneous EL4 and LL2 tumours, brain, heart, liver and kidneys $15 \mathrm{~s}$ after injection of $0.35 \mathrm{~mL} 100 \mathrm{mM}$ hyperpolarized $\left[\mathrm{U}-{ }^{2} \mathrm{H}\right.$, $\left.\mathrm{U}-{ }^{13} \mathrm{C}\right]$ glucose. The lactate spectra are the sum of four transients collected over $1 \mathrm{~s}$, whereas a single transient was acquired for the glucose spectra. Flux of the hyperpolarized ${ }^{13} \mathrm{C}$ label was only observed between $\left[\mathrm{U}_{-}{ }^{2} \mathrm{H}\right.$, $\left.\mathrm{U}-{ }^{13} \mathrm{C}\right]$ glucose $(63-99 \mathrm{ppm})$ and lactate $\mathrm{C} 1$ (doublet at about 185 ppm) in EL4 and LL2 tumours. b Representative chemical shift selective images obtained about $15 \mathrm{~s}$ after intravenous injection of $0.4 \mathrm{~mL} 200 \mathrm{mM}$ hyperpolarized $\left[\mathrm{U}^{2}{ }^{2} \mathrm{H}\right.$,

$\left.\mathrm{U}-{ }^{13} \mathrm{C}\right]$ glucose into an EL4 tumour-bearing mouse. The spatial distribution of glucose, urea and lactate are shown as voxel intensities relative to their respective maxima. The ${ }^{1} \mathrm{H}$ MR images, shown in grey scale, were used to define the anatomical location of the tumour (outlined in white). A urea phantom was included to serve as a reference. The colour scales represent arbitrary linearly distributed intensities for the hyperpolarized images. Reprinted from Rodrigues et al. [112] a

Glucose

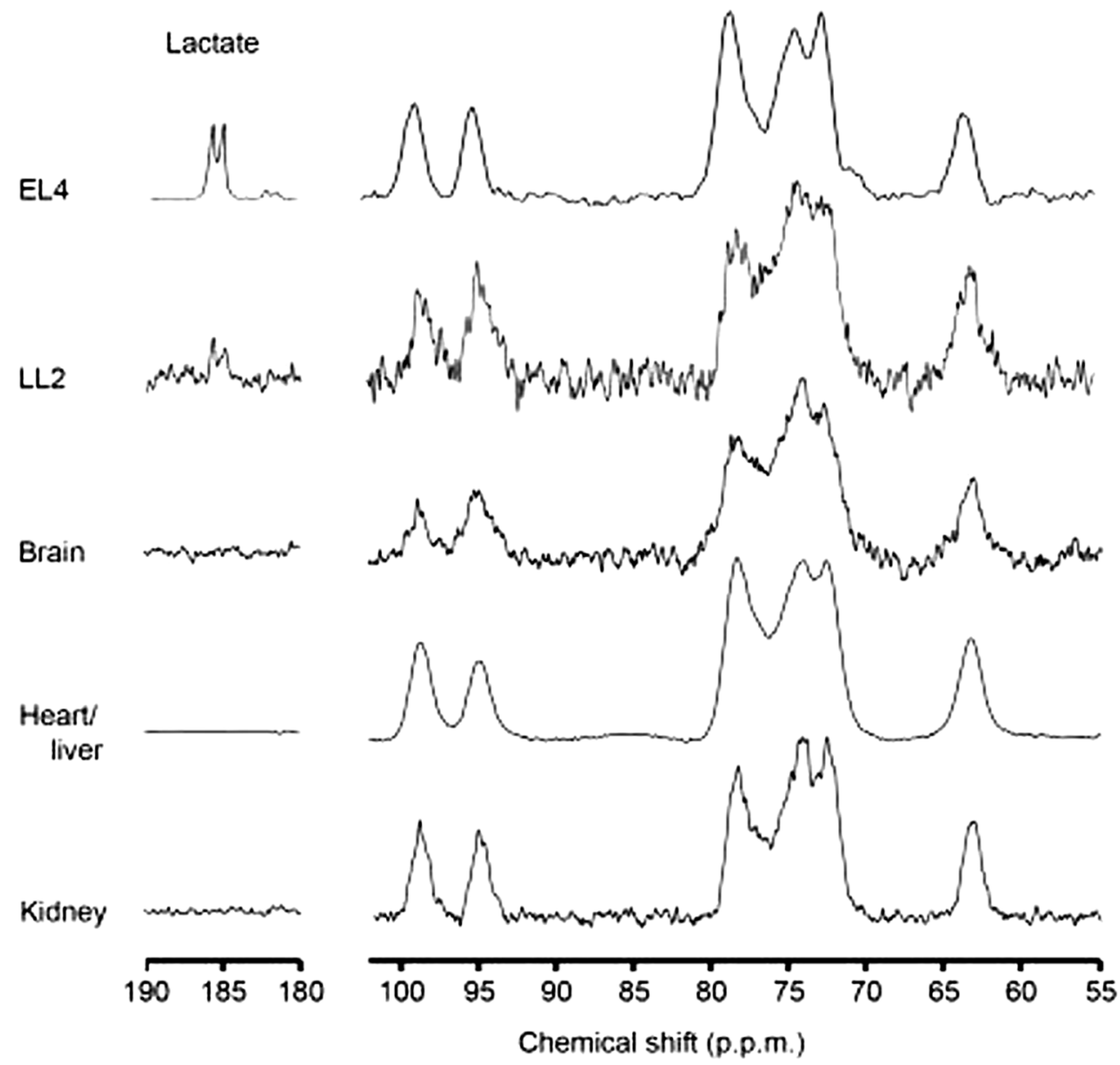

b

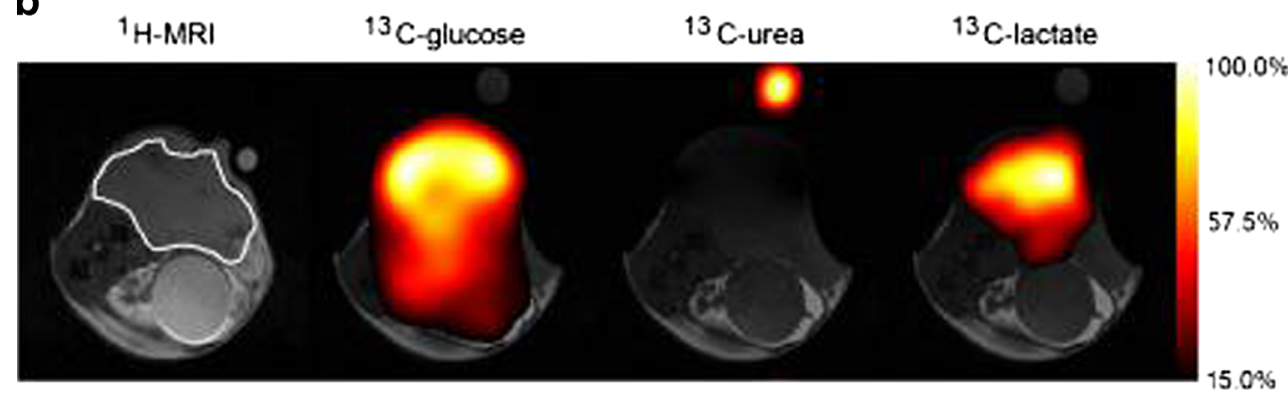

glutaminolysis in prostate tumour cell lines changed depending on their survival response after treatment with cytostatic drugs, and therefore argued that hyperpolarized $\left[5-{ }^{13} \mathrm{C}\right]$ glutamine metabolism is a promising biomarker for the noninvasive detection of tumour response to treatment.

In conclusion, imaging of the metabolic profile of tumours has already been part of clinical routine in cancer management. Current techniques, however, still have various limitations regarding sensitivity, specificity or applicability, and additional and alternative methods are needed. Various promising new techniques are under evaluation and multimodal imaging approaches may solve some the issues encountered [114].
Imaging tumour evasion and metastasis

One of the most critical factors in clinical cancer management is the degree of tumour evasion and the occurrence of (distant) metastasis. These features determine if local or systemic therapies are required and may be the basis for palliative rather than curative therapy. Routine molecular imaging technology using ${ }^{18}$ F-FDG (molecular marker: increased sugar metabolism) has revolutionized the noninvasive detection of tumour extent and metastatic spread for a great number of cancers (see above). Unfortunately, this highly generic approach is not always effective, meaning that some cancer types require more 
dedicated techniques. One example is the sentinel node procedure that is focused on the identification of (submillimetre) micrometastasis in the lymphatic track using lymphatic flow and accumulation by the immune system as molecular markers [115]. Early studies have shown that more personalized means to monitor the extent of oncological disease may benefit greatly from the use of molecular tumour markers [116-118]. As indicated in the Introduction, many clinical success stories in molecular imaging of specific cancer biomarkers can be found in which tumour-specific markers, such as SSTR-targeting peptides and HER-2 (EGFR2)-targeting antibodies, have been used [119-121]

A number of molecular targets are considered to be representative of metastatic disease and have provided the basis for the development and recent translation of innovative imaging agents. These targets include prostate-specific membrane antigen (PSMA), chemokine receptor 4 (CXCR4) and mesenchymal-epithelial transition factor (c-MET). PSMA is expressed both on the primary tumour and on prostate cancer-related metastasis, so it has the potential to visualize the full tumour load, including metastasis [122]. PSMA-based imaging agents described are based on molecules that differ in size, e.g. antibodies, nanobodies, aptamers and low molecular weight inhibitors of PSMA [116, 123-127]. The last of these in particular have shown high potential in mice and more recently also in humans [116]. Important to note here is that clinical PSMA PET is so effective that it might rapidly replace choline-based PET [128]. Although clinical trials with optical derivatives have not yet been reported, it has already become clear from preclinical studies that these small molecules remain efficient when a fluorescent dye is attached [129].

Based on the potential to drive migration along a stromal derived factor 1 (SDF-1) gradient, CXCR4 is considered a marker of malignant/metastatic disease. High expression levels of SDF-1 have been found at the most common sites of cancer metastasis, e.g. lymph nodes, lungs, liver and bone marrow. This makes CXCR4 a candidate target for molecular imaging to define the extent of disease and/or to identify highly aggressive subpopulations of tumour cells [130, 131]. Preclinical molecular imaging of CXCR4 is focused around SPECT, PET and optical imaging. Where the first two have shown potential for the noninvasive visualization of disease extent [132, 133], the last enables microscopic evaluation of receptor interactions and has demonstrated potential in imageguided surgery applications [134]. Studies regarding this receptor nicely illustrate that the efforts to optimize affinity and kinetics have paid off. Of all the new compounds tested in the preclinical setting, to our knowledge only one has made it to use in humans, namely $\left[{ }^{68} \mathrm{Ga}\right]$ pentixafor [135]

MET (a receptor tyrosine kinase) is an oncogene that plays a role in tumour metastasis and motility [136]. Tyrosine kinase MET is the receptor for hepatocyte growth factor (HGF/SF) and interaction between MET HGF/SF can induce scattering and migration of (tumour) progenitor cells. The general occurrence on carcinomas makes MET a marker for metastatic risk stratification. MET imaging has been pursued using different targeting moieties and different imaging labels. For example, anticalins and antibodies have been used to generate PET tracers for this receptor $[137,138]$. Both show activity in vitro and in mouse tumour models. Alternatively, peptides have been used to optically visualize MET in mice. Examples are the linear peptide cMBP-AOC-Cy5.5 [139] and the cyclic peptide GE137 (that also contains a Cy5-like dye) [140]. To our knowledge only the latter has so far found its way into clinical trials, where it has shown potential for fluorescenceguided surgery of colorectal neoplasia.

In conclusion, the recent successful development of tracers for PSMA, CXCR and c-MET indicates the value that exploratory preclinical studies have in the field of molecular imaging. Given the many ongoing preclinical imaging efforts, it is highly likely that more tracers for metastatic disease will find their way into the clinic. When this is the case, it is of course critical that they are evaluated beyond exploratory first-inhuman studies. Ultimately, (randomized) multicentre studies will be required to prove the clinical value of the new technologies.

Imaging inflammation and (evasion of) immune cells

Tumours harbour dynamic microenvironments in which cancer cells are associated with normal host cells. The tumourassociated stroma plays an important role during tumour growth, influencing events such as angiogenesis, metastasis and immune suppression [28, 141, 142]. As such, the stroma forms an attractive target for diagnostic and therapeutic applications. To distinguish normal from cancer cells, different strategies can be followed. Mice and other animal models can be created that use genetic reporters to label or track specific cells within the tumour or cells can be labelled with tumour-targeting or high-affinity molecules that contain radionuclides, fluorochromes or magnetic labels. Different myeloid cells are important components of the tumour stroma. Myeloid cells are frequently found to infiltrate tumours and have been linked to diverse tumour-promoting activities. In particular, tumour-associated macrophages (TAMs) are an important component of the tumour stroma [143]. Macrophages are plastic cells that can adopt different phenotypes depending on the immune context; microenvironmental stimuli can drive a macrophage either towards a "classical" (M1) or an "alternative" (M2) activation state, two extremes in a spectrum. M1 macrophages are typically characterized by the expression of proinflammatory cytokines, inducible nitric oxide synthase 2 and MHC class II molecules. M2 macrophages have a decreased level of these molecules, are identified by a malignant phenotype and their signature expression of a variety of markers, including arginase- 1 and mannose and several 
receptors. Strongly proangiogenic TAMs that reside in hypoxic tumour areas express high levels of macrophage mannose receptor (CD206) [144, 145].

It has been suggested that TAMs display an M2-like phenotype [144]. However, because of a lack of specific imaging agents, there is a poor understanding of their absolute numbers, flux rates and functional states in different tissues. Molecular probes for macrophage imaging target several aspects of macrophage cell biology. Cellular probes specific for membrane markers on the cell surface can localize macrophages within tissues, and surface proteins whose levels increase in stimulated cells can preferentially identify activated cells. Surface targets for macrophage imaging, although not specific for this cell type, include vascular cell adhesion protein-1 [146], receptors (folate receptor, SSTR subtype 2) [147, 148], intercellular adhesion molecule-1 [149], and chemokine receptors [150]. In addition to localization by targeting surface proteins, internalization of probes through phagocytosis by macrophages can also detect such cells preferentially; several nanoparticle-based and superparamagnetic probes show promise in this regard [151].

Cell-based therapies, such as immunotherapy and stem cell therapy, are most promising anticancer therapies; many forms of adoptive $T$ cell therapy are on the verge of being translated to the clinic $[43,152,153]$. The development of therapeutic strategies using tumour-targeted cells requires the ability to image and determine in vivo the location, distribution and viability of the therapeutic cells, as well as their biological fate with respect to cell activation and differentiation. Such celltracking methods, including labelling with, for example, $\left.{ }^{[111} \mathrm{In}\right]$ oxine, or magnetofluorescent techniques for cell labelling, play an important role in basic cancer research, where they serve to elucidate novel biological mechanisms [154-156].

In conclusion, it is expected that the material described, which allows visualization of the biology of macrophages and other immune cells in vivo in preclinical models, will also be useful for a multitude of human applications. Because of the implications of stromal cells and factors, this is an emerging field of potential targets for both imaging and therapy.

\section{Imaging cell death}

The currently most widely used therapy response criteria are based on size measurements of tumour lesions according to RECIST or WHO criteria [157]. However, lesion size changes after therapy may take a long time to occur, and lesion size may not always be reflective of actual response, i.e. eradication of tumour cells. Lesion size measurements are therefore considered not to be ideal for early response assessment, which is often desired in drug efficacy trials and treatment monitoring. This has led to a high level of interest in noninvasive methods for assessing tumour cell death following interventions, allowing early therapy response assessment [158].

Cell death is characterized by loss of cellular integrity that is mediated by a large variety of molecular changes including: externalization of phosphatidylserine to the outer leaflet of the plasma membrane bilayer, activation of effector caspases, depolarization of the plasma and mitochondrial membranes and loss of plasma membrane integrity $[159,160]$. All these processes have been studied as targets for imaging biomarkers with the presentation of phosphatidylserine residues at the outer surface of the plasma membrane being the most widely studied to date [158, 161]. For this target, annexin-V-based probes have been most frequently used, including probes suitable for imaging by MRI [162, 163], PET [164], SPECT [165], optical techniques [166, 167] and ultrasound molecular imaging [168]. However, despite promising results in clinical trials $[169,170]$, suboptimal biodistribution profiles of annexin-V tracers [171] have stimulated the search for other molecules that can bind to phosphatidylserine [172-174].

As well as phosphatidylserine exposure, detection of caspase activity has also been investigated as an imaging biomarker of cell death [175-178] and has even reached testing in early clinical trials [179]. Besides these two main molecular targets for cell death imaging, several other approaches are also being evaluated as (surrogate) markers of cell death. These involve imaging probes or imaging techniques that are able to visualize membrane depolarization or loss of membrane integrity. Regarding depolarization of membranes, triphenyl phosphonium-based probes $[68,180,181]$, and 2-(5fluoropentyl)-2-methyl malonic acid [182-184] have been found to show uptake characteristics in tumour tissue that could be linked to tumour cell death and reductions in tumour volume as verified by other imaging techniques or ex vivo analyses of tumour tissue.

Interest in two MRI techniques has recently been increasing as a means to image processes related to tumour cell death: diffusion-weighted (DW) MRI [185] and MRS of hyperpolarized fumarate [186]. DW MRI provides image contrast through measurement of the diffusion properties of water within tissues. By using sequential imaging with different weightings for diffusion an apparent diffusion coefficient (ADC) map can be generated. Water diffusion is restricted within cells and increases following loss of cellular integrity by which ADC DW imaging may be used to monitor cell death. Various in vivo studies have shown significant correlations between increases in ADC values in tumour tissue and response to treatment and apoptosis of tumour cells [187-190]. Due to loss of cellular integrity during cell death, fumarate can enter cells rapidly and is converted to malate. This process can be monitored by MRS of hyperpolarized [1, ${ }^{4-}{ }^{13} \mathrm{C}_{2}$ ] fumarate [186]. The sensitivity of this latter technique has even been shown to be superior to that of ADC DW imaging [189]. 
In conclusion, since eradication of tumour cells is the ultimate goal of anticancer therapy, cell death detection is considered of high importance for (early) response assessment. Several methods and probes are currently under investigation with questions still remaining regarding the choice of relevant imaging target and the timing of assessment $[1,158,191]$.

\section{Multifunctional probes}

Here we briefly introduce some concepts regarding multifunctional imaging probes such as theranostic and multimodality probes. As indicated above many of the molecular targets mentioned are also suitable as targets for targeted therapy. This has formed the basis for theranostics (theragnostics), the principle by which the same targeting molecule or particle can be used for both diagnosis and targeted therapy. This principle has been exploited in peptide receptor radionuclide therapy [9], but is also being considered a valuable strategy in the development and use of other therapeutics, e.g. biologicals and particle-based drug delivery systems such as liposomes, microcapsules and polymeric micelles [192, 193].

Multimodality probes consist of compounds that carry multiple signalling beacons by which they can be imaged by two or more imaging modalities [194, 195]. These compounds have the advantage that the strengths of different modalities can be combined, e.g. high sensitivity and high spatial resolution or quantitative performance, and may specifically play a role in image-guided drug delivery [193] and image-guided surgery [196].

\section{Specific challenges in preclinical imaging studies}

Preclinical studies in animal models are important for the development and evaluation of new imaging techniques and imaging probes. However, data obtained in in vivo molecular imaging studies in small animals may be influenced by the animal model used, by animal preparation and handling, and by the use of anaesthesia. Therefore, we briefly address some important issues to be taken into account during small-animal imaging in general (more detailed information can be obtained from the literature [197]).

The use of multimodality imaging may be very demanding for an animal, mostly because, in contrast to human studies, imaging of small animals generally requires anaesthesia. It is important to note that this may confound the results of imaging studies, as anaesthesia may influence many physiological parameters [198]. Such issues especially need to be taken into account when multimodality imaging studies are performed at regular time intervals. The feasibility of such studies is strongly dependent on parameters such as the total acquisition time, the type of anaesthesia administered, the surgical procedures required per imaging session and the body temperature of the anaesthetized animal, which depends on the use of a heated bed before and during scanning. Imaging conscious animals or imaging animals after death may avoid the issues with anaesthesia, but these approaches clearly have their own inherent disadvantages and problems. For ultrasound imaging, the type of carrier gas for isoflurane anaesthesia affects the longevity of the microbubbles. Longevity of nontargeted microbubbles is longer when medical air is used instead of oxygen [199-201]; this might also have implications for targeted microbubbles. On the other hand, longer persistence of freely floating targeted microbubbles would also prolong the ultrasound molecular imaging protocol as typically imaging is not performed until most freely floating targeted microbubbles are cleared from the circulation [73, 74]. However, new developments aiming at distinguishing adherent from freely floating targeted microbubbles form an active area of research.

Besides anaesthesia issues, ionizing radiation used in imaging studies can cause side effects and undesired antitumour effects. In small-animal imaging, often relatively high amounts of radioactivity have to be administered to produce high-resolution images within a reasonable acquisition time. In small-animal SPECT imaging, on a body weight basis, the activity dose is therefore up to 100 times higher than in the clinical setting. Funk et al. [202] estimated that the wholebody dose in preclinical SPECT and PET studies ranges between 6 and $90 \mathrm{cGy}$ in mice and between about 1 and $27 \mathrm{cGy}$ in rats. They concluded that the whole-body dose in smallanimal imaging can be very high in comparison to the lethal dose to mice. The dose should therefore be monitored carefully and the administered activity should be kept to a minimum. In follow-up SPECT/CT studies, the risk of side effects due to high radiation doses from consecutive scanning must be considered and dosimetry should be performed, and should also include the radiation dose delivered by (repeat) CT scans performed in SPECT/CT [203]. Willekens et al. [204] estimated that the median organ dose in mice from a standard microCT scan is about $40 \mathrm{cGy}$ and this may influence the experimental outcome, but adaptation of the scan protocol allows accurate imaging without the risk of interfering with the experimental outcome of the study. Note that high-resolution (high-dose) scanning can always be planned as a one-off scan or as the final CT scan of a longer nuclear scan series.

\section{Concluding remarks}

We have described a panel of biological targets derived from the "hallmarks of cancer" and indicated their potential for use as imaging biomarkers in oncology based on data obtained from preclinical studies in animal tumour models. Such 
preclinical studies are crucial in providing proof-of-concept in the development process of new imaging biomarkers for diagnostic, prognostic or early response monitoring purposes in patients. Furthermore, the use of imaging biomarkers in the preclinical setting is also of value in the evaluation of new drugs and tracers. It allows high-throughput assessment of basic safety, pharmacokinetics and target specificity of the compound of interest before clinical testing. While proof-ofconcept has been provided for some of the described imaging biomarkers, the majority still need further validation at both the preclinical and clinical level before they can qualify as robust imaging biomarkers.

Therefore, driven by medical need the search for new or improved imaging targets, imaging probes and (multimodal) imaging technologies will continue. Multimodality imaging is a promising new area in this respect. Recent imaging advances are synergistic with new imaging agents, reporters, better models and labelling options, so finally it is hoped that molecular imaging systems will allow clinicians to routinely 'see' expression and activity of specific molecules, cells and/or biological processes influencing tumour behaviour, that will answer important questions to ultimately offer cancer patients treatment tailored to their individual characteristics.

Acknowledgments This research was partly supported by the research programme Veni, which is financed by the Netherlands Organisation for Scientific Research (NWO) (K.K.), the Dutch Cancer Society - KWF (several grants; http://www.kwfkankerbestrijding.nl/Pages/Home.aspx), Applied Molecular Imaging Erasmus MC (AMIE) facility providing the imaging equipment, EU COST, EU ITN, Erasmus MC grants. The funders had no role in the study design, data collection and analysis, decision to publish, or preparation of the manuscript.

Open Access This article is distributed under the terms of the Creative Commons Attribution License which permits any use, distribution, and reproduction in any medium, provided the original author(s) and the source are credited.

\section{References}

1. European Society of Radiology. Medical imaging in personalised medicine: a white paper of the research committee of the European Society of Radiology (ESR). Insights Imaging. 2011;2(6):621-30.

2. Kessler LG, Barnhart HX, Buckler AJ, et al. The emerging science of quantitative imaging biomarkers terminology and definitions for scientific studies and regulatory submissions. Stat Methods Med Res. 2014. doi:10.1177/0962280214537333.

3. Society of Nuclear Medicine and Molecular Imaging. http://www. snmmi.org/Research/ClinicalTrialsNetwork.aspx? ItemNumber= 6831.

4. Radiological Society of North America. http://www.snmmi.org/ Research/ClinicalTrialsNetwork.aspx?ItemNumber $=6831$.

5. Biomarkers Definitions Working Group. Biomarkers and surrogate endpoints: preferred definitions and conceptual framework. Clin Pharmacol Ther. 2001;69(3):89-95.

6. Decristoforo C, Penuelas I, Elsinga P, et al. Radiopharmaceuticals are special, but is this recognized? The possible impact of the new clinical trials regulation on the preparation of radiopharmaceuticals. Eur J Nucl Med Mol Imaging. 2014;41(11):2005-7.

7. Bernsen MR, Vaissier PE, Van Holen R, Booij J, Beekman FJ, de Jong $\mathrm{M}$. The role of preclinical SPECT in oncological and neurological research in combination with either CT or MRI. Eur J Nucl Med Mol Imaging. 2014;41 Suppl 1:S36-49.

8. de Jong M, Essers J, van Weerden WM. Imaging preclinical tumour models: improving translational power. Nat Rev Cancer. 2014;14(7):481-93.

9. Ambrosini V, Fani M, Fanti S, Forrer F, Maecke HR. Radiopeptide imaging and therapy in Europe. J Nucl Med. 2011;52 Suppl 2:42S$55 \mathrm{~S}$.

10. Gros SJ, Dohrmann T, Peldschus K, et al. Complementary use of fluorescence and magnetic resonance imaging of metastatic esophageal cancer in a novel orthotopic mouse model. Int $\mathrm{J}$ Cancer. 2010;126(11):2671-81.

11. Hoffman RM. The multiple uses of fluorescent proteins to visualize cancer in vivo. Nat Rev Cancer. 2005;5(10):796-806.

12. Krupnick AS, Tidwell VK, Engelbach JA, et al. Quantitative monitoring of mouse lung tumors by magnetic resonance imaging. Nat Protoc. 2012;7(1):128-42.

13. O’Neill K, Lyons SK, Gallagher WM, Curran KM, Byrne AT. Bioluminescent imaging: a critical tool in pre-clinical oncology research. J Pathol. 2010;220(3):317-27.

14. Rossin R, Verkerk PR, van den Bosch SM, et al. In vivo chemistry for pretargeted tumor imaging in live mice. Angew Chem Int Ed Engl. 2010;49(19):3375-8.

15. Wolf G, Abolmaali N. Preclinical molecular imaging using PET and MRI. Recent Results Cancer Res. 2013;187:257-310.

16. Zhang X, Bloch S, Akers W, Achilefu S. Near-infrared molecular probes for in vivo imaging. Curr Protoc Cytom. 2012; Chapter 12: Unit12.27. doi:10.1002/0471142956.cy1227s60.

17. Louie A. Multimodality imaging probes: design and challenges. Chem Rev. 2010;110(5):3146-95.

18. Zhang Z, Fan J, Cheney PP, et al. Activatable molecular systems using homologous near-infrared fluorescent probes for monitoring enzyme activities in vitro, in cellulo, and in vivo. Mol Pharm. 2009;6(2):416-27.

19. Bednar B, Ntziachristos V. Opto-acoustic imaging of drug discovery biomarkers. Curr Pharm Biotechnol. 2012;13(11):2117-27.

20. Elsabahy M, Wooley KL. Design of polymeric nanoparticles for biomedical delivery applications. Chem Soc Rev. 2012;41(7): 2545-61.

21. Kosaka N, Bernardo M, Mitsunaga M, Choyke PL, Kobayashi H. MR and optical imaging of early micrometastases in lymph nodes: triple labeling with nano-sized agents yielding distinct signals. Contrast Media \& Mol Imaging. 2012;7(2):247-53.

22. Xu C, Zhao W. Nanoparticle-based monitoring of stem cell therapy. Theranostics. 2013;3(8):616-7.

23. Zhang Z, Dharmakumar R, Mascheri N, Fan Z, Wu S, Li D. Comparison of superparamagnetic and ultrasmall superparamagnetic iron oxide cell labeling for tracking green fluorescent protein gene marker with negative and positive contrast magnetic resonance imaging. Mol Imaging. 2009;8(3):148-55.

24. Unnikrishnan S, Klibanov AL. Microbubbles as ultrasound contrast agents for molecular imaging: preparation and application. AJR Am J Roentgenol. 2012;199(2):292-9.

25. Klibanov AL. Preparation of targeted microbubbles: ultrasound contrast agents for molecular imaging. Med Biol Eng Comput. 2009;47(8):875-82.

26. Barrefelt AA, Brismar TB, Egri G, et al. Multimodality imaging using SPECT/CT and MRI and ligand functionalized $99 \mathrm{mTc}-$ labeled magnetic microbubbles. EJNMMI Res. 2013;3(1):12.

27. Kenny GD, Bienemann AS, Tagalakis AD, et al. Multifunctional receptor-targeted nanocomplexes for the delivery of therapeutic nucleic acids to the brain. Biomaterials. 2013;34(36):9190-200. 
28. Hanahan D, Coussens LM. Accessories to the crime: functions of cells recruited to the tumor microenvironment. Cancer Cell. 2012;21(3):309-22.

29. Hanahan D, Weinberg RA. Hallmarks of cancer: the next generation. Cell. 2011;144(5):646-74.

30. Heskamp S, van Laarhoven HW, Oyen WJ, van der Graaf WT, Boerman OC. Tumor-receptor imaging in breast cancer: a tool for patient selection and response monitoring. Curr Mol Med. 2013;13(10):1506-22.

31. Jadvar H. Molecular imaging of prostate cancer with PET. J Nucl Med. 2013;54(10):1685-8.

32. Pepe G, Moncayo R, Bombardieri E, Chiti A. Somatostatin receptor SPECT. Eur J Nucl Med Mol Imaging. 2012;39 Suppl 1:S41-51.

33. Oliveira S, Heukers R, Sornkom J, Kok RJ, van Bergen En Henegouwen PM. Targeting tumors with nanobodies for cancer imaging and therapy. J Control Release. 2013;172(3):607-17.

34. Malonne H, Langer I, Kiss R, Atassi G. Mechanisms of tumor angiogenesis and therapeutic implications: angiogenesis inhibitors. Clin Exp Metastasis. 1999;17(1):1-14.

35. Bading JR, Shields AF. Imaging of cell proliferation: status and prospects. J Nucl Med. 2008;49 Suppl 2:64S-80S.

36. Lu L, Samuelsson L, Bergstrom M, Sato K, Fasth KJ, Langstrom B. Rat studies comparing 11C-FMAU, 18F-FLT, and 76Br-BFU as proliferation markers. J Nucl Med. 2002;43(12):1688-98.

37. Chalkidou A, Landau DB, Odell EW, Cornelius VR, O'Doherty MJ, Marsden PK. Correlation between Ki-67 immunohistochemistry and $18 \mathrm{~F}$-fluorothymidine uptake in patients with cancer: a systematic review and meta-analysis. Eur J Cancer. 2012;48(18):3499513.

38. Sugiyama M, Sakahara H, Sato K, et al. Evaluation of 3'-deoxy-3'$18 \mathrm{~F}$-fluorothymidine for monitoring tumor response to radiotherapy and photodynamic therapy in mice. J Nucl Med. 2004;45(10):1754 8.

39. Leyton J, Latigo JR, Perumal M, Dhaliwal H, He Q, Aboagye EO. Early detection of tumor response to chemotherapy by 3'-deoxy-3'[18F]fluorothymidine positron emission tomography: the effect of cisplatin on a fibrosarcoma tumor model in vivo. Cancer Res. 2005;65(10):4202-10.

40. Leyton J, Alao JP, Da Costa M, et al. In vivo biological activity of the histone deacetylase inhibitor LAQ824 is detectable with 3'-deoxy-3'-[18F] fluorothymidine positron emission tomography. Cancer Res. 2006;66(15):7621-9.

41. Waldherr C, Mellinghoff IK, Tran C, et al. Monitoring antiproliferative responses to kinase inhibitor therapy in mice with 3'-deoxy-3'18F-fluorothymidine PET. J Nucl Med. 2005;46(1):114-20.

42. Muzi M, Vesselle H, Grierson JR, et al. Kinetic analysis of 3'-deoxy-3'-fluorothymidine PET studies: validation studies in patients with lung cancer. J Nucl Med. 2005;46(2):274-82.

43. Liu Z, Li Z. Molecular imaging in tracking tumor-specific cytotoxic T lymphocytes (CTLs). Theranostics. 2014;4(10):990-1001.

44. Woolf DK, Beresford M, Li SP, et al. Evaluation of FLT-PET-CT as an imaging biomarker of proliferation in primary breast cancer. Br J Cancer. 2014;110(12):2847-54.

45. Hong Y, Sang M, Shang C, Xue YX, Liu YH. Quantitative analysis of topoisomerase II alpha and evaluation of its effects on cell proliferation and apoptosis in glioblastoma cancer stem cells. Neurosci Lett. 2012;518(2):138-43.

46. Lyu YL, Kerrigan JE, Lin CP, et al. Topoisomerase Ilbeta mediated DNA double-strand breaks: implications in doxorubicin cardiotoxicity and prevention by dexrazoxane. Cancer Res. 2007;67(18):8839-46.

47. Tokiniwa H, Horiguchi J, Takata D, et al. Topoisomerase II alpha expression and the $\mathrm{Ki}-67$ labeling index correlate with prognostic factors in estrogen receptor-positive and human epidermal growth factor type-2-negative breast cancer. Breast Cancer. 2012;19(4): 309-14.
48. Daumar P, Zeglis BM, Ramos N, et al. Synthesis and evaluation of F-labeled ATP competitive inhibitors of topoisomerase II as probes for imaging topoisomerase II expression. Eur J Med Chem. 2014;86C:769-81.

49. Wei L, Easmon J, Nagi RK, Muegge BD, Meyer LA, Lewis JS. 64Cu-azabicyclo[3.2.2] nonane thiosemicarbazone complexes: radiopharmaceuticals for PET of topoisomerase II expression in tumors. J Nucl Med. 2006;47(12):2034-41.

50. van Waarde A, Rybczynska AA, Ramakrishnan N, Ishiwata K, Elsinga PH, Dierckx RA. Sigma receptors in oncology: therapeutic and diagnostic applications of sigma ligands. Curr Pharm Des. 2010;16(31):3519-37.

51. van Waarde A, Rybczynska AA, Ramakrishnan NK, Ishiwata K, Elsinga PH, Dierckx RA. Potential applications for sigma receptor ligands in cancer diagnosis and therapy. Biochim Biophys Acta. 2014. doi:10.1016/j.bbamem.2014.08.022.

52. Mach RH, Zeng C, Hawkins WG. The sigma2 receptor: a novel protein for the imaging and treatment of cancer. J Med Chem. 2013;56(18):7137-60.

53. Zeng C, Vangveravong S, Jones LA, et al. Characterization and evaluation of two novel fluorescent sigma-2 receptor ligands as proliferation probes. Mol Imaging. 2011;10(6):420-33.

54. Tu Z, Xu J, Jones LA, et al. Fluorine-18-labeled benzamide analogues for imaging the sigma 2 receptor status of solid tumors with positron emission tomography. J Med Chem. 2007;50(14):3194 204.

55. Mach RH, Dehdashti F, Wheeler KT. PET radiotracers for imaging the proliferative status of solid tumors. PET Clin. 2009;4(1):1-15.

56. Dehdashti F, Laforest R, Gao F, et al. Assessment of cellular proliferation in tumors by PET using $18 \mathrm{~F}-\mathrm{ISO}-1$. J Nucl Med. 2013;54(3):350-7.

57. Shoghi KI, Xu J, Su Y, et al. Quantitative receptor-based imaging of tumor proliferation with the sigma-2 ligand [(18)F]ISO-1. PLoS One. 2013;8(9):e74188.

58. Cao Y. The promise of dynamic contrast-enhanced imaging in radiation therapy. Semin Radiat Oncol. 2011;21(2):147-56.

59. O'Connor JP, Jackson A, Parker GJ, Roberts C, Jayson GC. Dynamic contrast-enhanced MRI in clinical trials of antivascular therapies. Nat Rev Clin Oncol. 2012;9(3):167-77.

60. Murakami T, Imai Y, Okada M, et al. Ultrasonography, computed tomography and magnetic resonance imaging of hepatocellular carcinoma: toward improved treatment decisions. Oncology. 2011;81 Suppl 1:86-99.

61. Bol K, Haeck JC, Groen HC, et al. Can DCE-MRI explain the heterogeneity in radiopeptide uptake imaged by SPECT in a pancreatic neuroendocrine tumor model? PLoS One. 2013;8(10): e77076.

62. Iltis I, Choi J, Vollmers M, Shenoi M, Bischof J, Metzger GJ. In vivo detection of the effects of preconditioning on $\mathrm{LNCaP}$ tumors by a TNF-alpha nanoparticle construct using MRI. NMR Biomed. 2014;27(9):1063-9.

63. Wu L, Lv P, Zhang H, et al. Dynamic contrast-enhanced (DCE) MRI assessment of microvascular characteristics in the murine orthotopic pancreatic cancer model. Magn Reson Imaging. 2014. doi:10.1016/j.mri.2014.08.014.

64. Alic L, Haeck JC, Bol K, et al. Facilitating tumor functional assessment by spatially relating 3D tumor histology and in vivo MRI: image registration approach. PLoS One. 2011;6(8):e22835.

65. Jost G, Pietsch H, Grenacher L. Dynamic contrast-enhanced computed tomography to assess antitumor treatment effects: comparison of two contrast agents with different pharmacokinetics. Invest Radiol. 2013;48(10):715-21.

66. Zhang X, Pagel MD, Baker AF, Gillies RJ. Reproducibility of magnetic resonance perfusion imaging. PLoS One. 2014;9(2):e89797. 
67. Zhao D, Jiang L, Hahn EW, Mason RP. Comparison of $1 \mathrm{H}$ blood oxygen level-dependent (BOLD) and 19F MRI to investigate tumor oxygenation. Magn Reson Med. 2009;62(2):357-64.

68. Zhao G, Yu YM, Shoup TM, et al. Membrane potential-dependent uptake of $18 \mathrm{~F}$-triphenylphosphonium - a new voltage sensor as an imaging agent for detecting burn-induced apoptosis. J Surg Res. 2014;188(2):473-9.

69. Xu H, Li B, Yu W, et al. Correlation between 18F-FDG uptake and the expression of glucose transporter-1 and hypoxia-inducible factor-1alpha in transplanted VX2 tumors. Nucl Med Commun. 2013;34(10):953-8.

70. Ganesan P, Moulder S, Lee JJ, et al. Triple-negative breast cancer patients treated at MD Anderson Cancer Center in phase I trials: improved outcomes with combination chemotherapy and targeted agents. Mol Cancer Ther. 2014;13(12):3175-84.

71. Contois LW, Akalu A, Caron JM, et al. Inhibition of tumorassociated $\alpha \mathrm{v} \beta 3$ integrin regulates the angiogenic switch by enhancing expression of IGFBP-4 leading to reduced melanoma growth and angiogenesis in vivo. Angiogenesis. 2015;18(1):31-46.

72. Schweizer MT, Carducci MA. From bevacizumab to tasquinimod: angiogenesis as a therapeutic target in prostate cancer. Cancer $\mathrm{J}$. 2013;19(1):99-106.

73. Kiessling F, Bzyl J, Fokong S, Siepmann M, Schmitz G, Palmowski M. Targeted ultrasound imaging of cancer: an emerging technology on its way to clinics. Curr Pharm Des. 2012;18(15):2184-99.

74. Deshpande N, Needles A, Willmann JK. Molecular ultrasound imaging: current status and future directions. Clin Radiol. 2010;65(7): $567-81$.

75. Grouls C, Hatting M, Rix A, et al. Liver dysplasia: US molecular imaging with targeted contrast agent enables early assessment. Radiology. 2013;267(2):487-95.

76. Baron Toaldo M, Salvatore V, Marinelli S, et al. Use of VEGFR-2 targeted ultrasound contrast agent for the early evaluation of response to sorafenib in a mouse model of hepatocellular carcinoma. Mol Imaging Biol. 2014. doi:10.1007/s11307-014-0764-x.

77. Korpanty G, Carbon JG, Grayburn PA, Fleming JB, Brekken RA. Monitoring response to anticancer therapy by targeting microbubbles to tumor vasculature. Clin Cancer Res. 2007;13(1): 323-30.

78. Palmowski M, Huppert J, Ladewig G, et al. Molecular profiling of angiogenesis with targeted ultrasound imaging: early assessment of antiangiogenic therapy effects. Mol Cancer Ther. 2008;7(1):101-9.

79. Pysz MA, Foygel K, Rosenberg J, Gambhir SS, Schneider M, Willmann JK. Antiangiogenic cancer therapy: monitoring with molecular US and a clinically translatable contrast agent (BR55). Radiology. 2010;256(2):519-27.

80. Sirsi SR, Flexman ML, Vlachos F, et al. Contrast ultrasound imaging for identification of early responder tumor models to antiangiogenic therapy. Ultrasound Med Biol. 2012;38(6):1019-29.

81. Streeter JE, Herrera-Loeza SG, Neel NF, Yeh JJ, Dayton PA. A comparative evaluation of ultrasound molecular imaging, perfusion imaging, and volume measurements in evaluating response to therapy in patient-derived xenografts. Technol Cancer Res Treat. 2013;12(4):311-21.

82. Wijkstra H, Smeenge M, de la Rosette J, Pochon S, Tardy-Cantalupi I, Tranquart F. Targeted microbubble prostate cancer imaging with BR55. Proceedings of the 17th European Symposium on Ultrasound Contrast Imaging, Rotterdam, 18-20 January 2012. Abstract book, p. 6-7. ClinicalTrials.gov Identifier: NCT01253213.

83. Shariff MI, Cox IJ, Gomaa AI, Khan SA, Gedroyc W, TaylorRobinson SD. Hepatocellular carcinoma: current trends in worldwide epidemiology, risk factors, diagnosis and therapeutics. Expert Rev Gastroenterol Hepatol. 2009;3(4):353-67.

84. Ostergaard L, Tietze A, Nielsen T, et al. The relationship between tumor blood flow, angiogenesis, tumor hypoxia, and aerobic glycolysis. Cancer Res. 2013;73(18):5618-24.
85. Bussink J, Kaanders JH, Strik AM, Vojnovic B, van Der Kogel AJ. Optical sensor-based oxygen tension measurements correspond with hypoxia marker binding in three human tumor xenograft lines. Radiat Res. 2000;154(5):547-55.

86. Xu Y, Zanganeh S, Mohammad I, et al. Targeting tumor hypoxia with 2-nitroimidazole-indocyanine green dye conjugates. J Biomed Opt. 2013;18(6):66009.

87. Shi Y, Oeh J, Eastham-Anderson J, et al. Mapping in vivo tumor oxygenation within viable tumor by $19 \mathrm{~F}-\mathrm{MRI}$ and multispectral analysis. Neoplasia. 2013;15(11):1241-50.

88. Gulaka PK, Rojas-Quijano F, Kovacs Z, Mason RP, Sherry AD, Kodibagkar VD. GdDO3NI, a nitroimidazole-based T1 MRI contrast agent for imaging tumor hypoxia in vivo. J Biol Inorg Chem. 2014;19(2):271-9.

89. Cai K, Shore A, Singh A, et al. Blood oxygen level dependent angiography (BOLDangio) and its potential applications in cancer research. NMR Biomed. 2012;25(10):1125-32.

90. Gerling M, Zhao Y, Nania S, et al. Real-time assessment of tissue hypoxia in vivo with combined photoacoustics and high-frequency ultrasound. Theranostics. 2014;4(6):604-13.

91. Lopci E, Grassi I, Chiti A, et al. PET radiopharmaceuticals for imaging of tumor hypoxia: a review of the evidence. Am J Nucl Med Mol Imaging. 2014;4(4):365-84.

92. Chitneni SK, Bida GT, Zalutsky MR, Dewhirst MW. Comparison of the hypoxia PET tracer 18F-EF5 to immunohistochemical marker EF5 in 3 different human tumor xenograft models. J Nucl Med. 2014;55(7):1192-7.

93. Jadvar H, Alavi A, Gambhir SS. 18F-FDG uptake in lung, breast, and colon cancers: molecular biology correlates and disease characterization. J Nucl Med. 2009;50(11):1820-7.

94. Wahl RL, Jacene H, Kasamon Y, Lodge MA. From RECIST to PERCIST: evolving considerations for PET response criteria in solid tumors. J Nucl Med. 2009;50 Suppl 1:122S-50S.

95. Cheng G, Torigian DA, Zhuang H, Alavi A. When should we recommend use of dual time-point and delayed time-point imaging techniques in FDG PET? Eur J Nucl Med Mol Imaging. 2013;40(5):779-87.

96. Huang C, McConathy J. Radiolabeled amino acids for oncologic imaging. J Nucl Med. 2013;54(7):1007-10.

97. Glunde K, Ackerstaff E, Mori N, Jacobs MA, Bhujwalla ZM. Choline phospholipid metabolism in cancer: consequences for molecular pharmaceutical interventions. Mol Pharm. 2006;3(5):496506.

98. Haberkorn U, Markert A, Mier W, Askoxylakis V, Altmann A. Molecular imaging of tumor metabolism and apoptosis. Oncogene. 2011;30(40):4141-51.

99. Kitajima K, Murphy RC, Nathan MA. Choline PET/CT for imaging prostate cancer: an update. Ann Nucl Med. 2013;27(7):581-91.

100. Treglia G, Giovannini E, Di Franco D, et al. The role of positron emission tomography using carbon- 11 and fluorine- 18 choline in tumors other than prostate cancer: a systematic review. Ann Nucl Med. 2012;26(6):451-61.

101. Schwarzenbock SM, Gertz J, Souvatzoglou M, et al. Comparison of $[11 \mathrm{C}]$ choline $([11 \mathrm{C}] \mathrm{CHO})$ and $\mathrm{S}(+)$-beta-methyl-[11C $]$ choline ([11C]SMC) as imaging probes for prostate cancer in a PC-3 prostate cancer xenograft model. Mol Imaging Biol. 2014. doi:10.1007/ s11307-014-0782-8.

102. Emonds KM, Swinnen JV, Lerut E, Koole M, Mortelmans L, Mottaghy FM. Evaluation of androgen-induced effects on the uptake of [18F]FDG, [11C]choline and [11C]acetate in an androgensensitive and androgen-independent prostate cancer xenograft model. EJNMMI Res. 2013;3(1):31.

103. Kauppinen RA, Peet AC. Using magnetic resonance imaging and spectroscopy in cancer diagnostics and monitoring: preclinical and clinical approaches. Cancer Biol Ther. 2011;12(8):665-79. 
104. Bezabeh T, Ijare OB, Nikulin AE, Somorjai RL, Smith IC. MRSbased metabolomics in cancer research. Magn Reson Insights. 2014;7:1-14.

105. Thomas MA, Nagarajan R, Huda A, et al. Multidimensional MR spectroscopic imaging of prostate cancer in vivo. NMR Biomed. 2014;27(1):53-66.

106. Spur EM, Decelle EA, Cheng LL. Metabolomic imaging of prostate cancer with magnetic resonance spectroscopy and mass spectrometry. Eur J Nucl Med Mol Imaging. 2013;40 Suppl 1:S60-71.

107. Zhai G, Kim H, Sarver D, et al. Early therapy assessment of combined anti-DR5 antibody and carboplatin in triple-negative breast cancer xenografts in mice using diffusion-weighted imaging and $1 \mathrm{H}$ MR spectroscopy. J Magn Reson Imaging. 2014;39(6):1588-94.

108. Baek HM, Lee YJ. Feasibility of MR spectroscopy for characterizing malignant breast lesions using a clinical 3-T scanner. Breast Cancer. 2014. doi:10.1007/s12282-013-0514-y.

109. Brindle KM, Bohndiek SE, Gallagher FA, Kettunen MI. Tumor imaging using hyperpolarized $13 \mathrm{C}$ magnetic resonance spectroscopy. Magn Reson Med. 2011;66(2):505-19.

110. Ardenkjaer-Larsen JH, Fridlund B, Gram A, et al. Increase in signalto-noise ratio of $>10,000$ times in liquid-state NMR. Proc Natl Acad Sci U S A. 2003;100(18):10158-63.

111. Hu S, Balakrishnan A, Bok RA, et al. 13C-pyruvate imaging reveals alterations in glycolysis that precede c-Myc-induced tumor formation and regression. Cell Metab. 2011;14(1):131-42.

112. Rodrigues TB, Serrao EM, Kennedy BW, Hu DE, Kettunen MI, Brindle KM. Magnetic resonance imaging of tumor glycolysis using hyperpolarized 13C-labeled glucose. Nat Med. 2014;20(1):93-7.

113. Canapè $C$, Catanzaro G, Terreno E, Karlsson M, Lerche MH, Jensen PR. Probing treatment response of glutaminolytic prostate cancer cells to natural drugs with hyperpolarized [5-13C]glutamine. Magn Reson Med. 2014. doi:10.1002/mrm.25360

114. Wehrl HF, Schwab J, Hasenbach K, et al. Multimodal elucidation of choline metabolism in a murine glioma model using magnetic resonance spectroscopy and 11C-choline positron emission tomography. Cancer Res. 2013;73(5):1470-80.

115. Nieweg OE. Lymphatics of the breast and the rationale for different injection techniques. Ann Surg Oncol. 2001;8(9 Suppl):71S-3S.

116. Cho SY, Gage KL, Mease RC, et al. Biodistribution, tumor detection, and radiation dosimetry of $18 \mathrm{~F}-\mathrm{DCFBC}$, a low-molecularweight inhibitor of prostate-specific membrane antigen, in patients with metastatic prostate cancer. J Nucl Med. 2012;53(12):1883-91.

117. Sodee DB, Sodee AE, Bakale G. Synergistic value of single-photon emission computed tomography/computed tomography fusion to radioimmunoscintigraphic imaging of prostate cancer. Semin Nucl Med. 2007;37(1):17-28.

118. de Herder WW, Kwekkeboom DJ, Valkema R, et al. Neuroendocrine tumors and somatostatin: imaging techniques. J Endocrinol Invest. 2005;11(28):132-6.

119. Niu G, Cai W, Chen X. Molecular imaging of human epidermal growth factor receptor 2 (HER-2) expression. Front Biosci. 2008;13:790-805.

120. van Essen M, Sundin A, Krenning EP, Kwekkeboom DJ. Neuroendocrine tumours: the role of imaging for diagnosis and therapy. Nat Rev Endocrinol. 2014;10(2):102-14.

121. Bai M, Bornhop DJ. Recent advances in receptor-targeted fluorescent probes for in vivo cancer imaging. Curr Med Chem. 2012;19(28):4742-58.

122. Mease RC, Foss CA, Pomper MG. PET imaging in prostate cancer: focus on prostate-specific membrane antigen. Curr Top Med Chem. 2013;13(8):951-62.

123. Wiehr S, Buhler P, Gierschner D, et al. Pharmacokinetics and PET imaging properties of two recombinant anti-PSMA antibody fragments in comparison to their parental antibody. Prostate. 2014;74(7):743-55.
124. Rockey WM, Huang L, Kloepping KC, Baumhover NJ, Giangrande PH, Schultz MK. Synthesis and radiolabeling of chelator-RNA aptamer bioconjugates with copper-64 for targeted molecular imaging. Bioorg Med Chem. 2011;19(13):4080-90.

125. Eder M, Schafer M, Bauder-Wust U, Haberkorn U, Eisenhut M, Kopka K. Preclinical evaluation of a bispecific low-molecular heterodimer targeting both PSMA and GRPR for improved PET imaging and therapy of prostate cancer. Prostate. 2014;74(6):659-68.

126. Chen Y, Pullambhatla M, Banerjee SR, et al. Synthesis and biological evaluation of low molecular weight fluorescent imaging agents for the prostate-specific membrane antigen. Bioconjug Chem. 2012;23(12):2377-85.

127. Chatalic KLS, Konijnenberg M, Maina T, et al. Enhancing the theranostic potential of the GRPR-antagonist JMV4168 for PET imaging and radionuclide therapy of prostate cancer. Eur J Nucl Med Mol Imaging. 2014;41(2):S176.

128. Afshar-Oromieh A, Haberkorn U, Schlemmer HP, et al. Comparison of PET/CT and PET/MRI hybrid systems using a 68Ga-labelled PSMA ligand for the diagnosis of recurrent prostate cancer: initial experience. Eur J Nucl Med Mol Imaging. 2014;41(5):887-97.

129. Kelderhouse LE, Chelvam V, Wayua C, et al. Development of tumor-targeted near infrared probes for fluorescence guided surgery. Bioconjug Chem. 2013;24(6):1075-80.

130. Kuil J, Buckle T, van Leeuwen FW. Imaging agents for the chemokine receptor 4 (CXCR4). Chem Soc Rev. 2012;41(15):5239-61.

131. Demmer O, Dijkgraaf I, Schumacher U, et al. Design, synthesis, and functionalization of dimeric peptides targeting chemokine receptor CXCR4. J Med Chem. 2011;54(21):7648-62.

132. Gourni E, Demmer O, Schottelius M, et al. PET of CXCR4 expression by a $68 \mathrm{Ga}$-labeled highly specific targeted contrast agent. J Nucl Med. 2011;52(11):1803-10.

133. De Silva RA, Peyre K, Pullambhatla M, Fox JJ, Pomper MG, Nimmagadda $\mathrm{S}$. Imaging CXCR4 expression in human cancer xenografts: evaluation of monocyclam 64Cu-AMD3465. J Nucl Med. 2011;52(6):986-93.

134. Buckle T, Kuil J, van den Berg NS, et al. Use of a single hybrid imaging agent for integration of target validation with in vivo and ex vivo imaging of mouse tumor lesions resembling human DCIS. PLoS One. 2013;8(1):e48324.

135. Wester H, Beer A, Keller U, et al. Imaging of CXCR4 chemokine receptor expression with [68Ga]pentixafor: first experience in cancer patients. J Nucl Med. 2014;55 Suppl 1:118.

136. Birchmeier C, Birchmeier W, Gherardi E, Vande Woude GF. Met, metastasis, motility and more. Nat Rev Mol Cell Biol. 2003;4(12): 915-25.

137. Jagoda EM, Lang L, Bhadrasetty V, et al. Immuno-PET of the hepatocyte growth factor receptor Met using the 1-armed antibody onartuzumab. J Nucl Med. 2012;53(10):1592-600.

138. van Scheltinga AG T, Lub-de Hooge MN, Hinner MJ, et al. In vivo visualization of MET tumor expression and anticalin biodistribution with the MET-specific anticalin 89Zr-PRS-110 PET tracer. J Nucl Med. 2014;55(4):665-71.

139. Kim EM, Park EH, Cheong SJ, et al. In vivo imaging of mesenchymal-epithelial transition factor (c-Met) expression using an optical imaging system. Bioconjug Chem. 2009;20(7):1299306.

140. Burggraaf et al., Nat Med, 2015, In press.

141. Bernsen MR, Ruggiero A, van Straten M, et al. Computed tomography and magnetic resonance imaging. Recent Results Cancer Res. 2013;187:3-63.

142. Narunsky L, Oren R, Bochner F, Neeman M. Imaging aspects of the tumor stroma with therapeutic implications. Pharmacol Ther. 2014;141(2):192-208. 
143. Schmid MC, Varner JA. Myeloid cells in the tumor microenvironment: modulation of tumor angiogenesis and tumor inflammation. $\mathrm{J}$ Oncol. 2010;2010:201026.

144. Chanmee T, Ontong P, Konno K, Itano N. Tumor-associated macrophages as major players in the tumor microenvironment. Cancers (Basel). 2014;6(3):1670-90.

145. Movahedi K, Schoonooghe S, Laoui D, et al. Nanobody-based targeting of the macrophage mannose receptor for effective in vivo imaging of tumor-associated macrophages. Cancer Res. 2012;72(16):4165-77.

146. Franklin RA, Liao W, Sarkar A, et al. The cellular and molecular origin of tumor-associated macrophages. Science. 2014;344(6186): 921-5.

147. Cascini GL, Cuccurullo V, Mansi L. The non tumour uptake of 111 Inoctreotide creates new clinical indications in benign diseases, but also in oncology. Q J Nucl Med Mol Imaging. 2010;54(1):24-36.

148. Muller C. Folate based radiopharmaceuticals for imaging and therapy of cancer and inflammation. Curr Pharm Des. 2012;18(8): 1058-83.

149. Ohtani H. Stromal reaction in cancer tissue: pathophysiologic significance of the expression of matrix-degrading enzymes in relation to matrix turnover and immune/inflammatory reactions. Pathol Int. 1998;48(1):1-9.

150. Yoshie O, Matsushima K. CCR4 and its ligands: from bench to bedside. Int Immunol. 2015;27(1):11-20.

151. Lameijer MA, Tang J, Nahrendorf M, Beelen RH, Mulder WJ. Monocytes and macrophages as nanomedicinal targets for improved diagnosis and treatment of disease. Expert Rev Mol Diagn. 2013;13(6):567-80.

152. Smith EL, Zamarin D, Lesokhin AM. Harnessing the immune system for cancer therapy. Curr Opin Oncol. 2014;26(6):600-7.

153. Stromnes IM, Schmitt TM, Chapuis AG, Hingorani SR, Greenberg PD. Re-adapting T cells for cancer therapy: from mouse models to clinical trials. Immunol Rev. 2014;257(1):145-64.

154. Ahrens ET, Bulte JW. Tracking immune cells in vivo using magnetic resonance imaging. Nat Rev Immunol. 2013;13(10):755-63.

155. Berglund D, Karlsson M, Palanisamy S, Carlsson B, Korsgren O, Eriksson O. Imaging the in vivo fate of human $\mathrm{T}$ cells following transplantation in immunoincompetent mice - implications for clinical cell therapy trials. Transpl Immunol. 2013;29(1-4):105-8.

156. Pittet MJ, Swirski FK, Reynolds F, Josephson L, Weissleder R. Labeling of immune cells for in vivo imaging using magnetofluorescent nanoparticles. Nat Protoc. 2006;1(1):73-9.

157. Jaffe CC. Measures of response: RECIST, WHO, and new alternatives. J Clin Oncol. 2006;24(20):3245-51.

158. Neves AA, Brindle KM. Imaging cell death. J Nucl Med. 2014;55(1):1-4.

159. Galluzzi L, Vitale I, Abrams JM, et al. Molecular definitions of cell death subroutines: recommendations of the Nomenclature Committee on Cell Death 2012. Cell Death Differ. 2012;19(1): 107-20.

160. Kreuzaler P, Watson CJ. Killing a cancer: what are the alternatives? Nat Rev Cancer. 2012;12(6):411-24.

161. Corsten MF, Hofstra L, Narula J, Reutelingsperger CP. Counting heads in the war against cancer: defining the role of annexin A5 imaging in cancer treatment and surveillance. Cancer Res. 2006;66(3):1255-60.

162. Figge L, Appler F, Chen HH, et al. Direct coupling of annexin A5 to VSOP yields small, protein-covered nanoprobes for MR imaging of apoptosis. Contrast Media Mol Imaging. 2014;9(4):291-9.

163. Schellenberger EA, Bogdanov Jr A, Hogemann D, Tait J, Weissleder R, Josephson L. Annexin V-CLIO: a nanoparticle for detecting apoptosis by MRI. Mol Imaging. 2002;1(2):102-7.

164. Blankenberg FG, Katsikis PD, Tait JF, et al. In vivo detection and imaging of phosphatidylserine expression during programmed cell death. Proc Natl Acad Sci U S A. 1998;95(11):6349-54.
165. Takei T, Kuge Y, Zhao S, et al. Time course of apoptotic tumor response after a single dose of chemotherapy: comparison with 99mTc-annexin V uptake and histologic findings in an experimental model. J Nucl Med. 2004;45(12):2083-7.

166. Dumont EA, Reutelingsperger CP, Smits JF, et al. Real-time imaging of apoptotic cell-membrane changes at the single-cell level in the beating murine heart. Nat Med. 2001;7(12):1352-5.

167. Schellenberger EA, Bogdanov Jr A, Petrovsky A, Ntziachristos V, Weissleder R, Josephson L. Optical imaging of apoptosis as a biomarker of tumor response to chemotherapy. Neoplasia. 2003;5(3): 187-92.

168. Wei X, Li Y, Zhang S, Gao X, Luo Y, Gao M. Ultrasound targeted apoptosis imaging in monitoring early tumor response of trastuzumab in a murine tumor xenograft model of her-2-positive breast cancer. Transl Oncol. 2014;7(2):284-91.

169. Belhocine T, Steinmetz N, Hustinx R, et al. Increased uptake of the apoptosis-imaging agent $(99 \mathrm{~m}) \mathrm{Tc}$ recombinant human Annexin V in human tumors after one course of chemotherapy as a predictor of tumor response and patient prognosis. Clin Cancer Res. 2002;8(9): 2766-74.

170. Yang TJ, Haimovitz-Friedman A, Verheij M. Anticancer therapy and apoptosis imaging. Exp Oncol. 2012;34(3):269-76.

171. Ogawa K, Ohtsuki K, Shibata T, et al. Development and evaluation of a novel $(99 \mathrm{~m}) \mathrm{Tc}$-labeled annexin A5 for early detection of response to chemotherapy. PLoS One. 2013;8(12):e81191.

172. Alam IS, Neves AA, Witney TH, Boren J, Brindle KM. Comparison of the $\mathrm{C} 2 \mathrm{~A}$ domain of synaptotagmin-I and annexin- $\mathrm{V}$ as probes for detecting cell death. Bioconjug Chem. 2010;21(5):884-91.

173. Niu G, Chen X. Apoptosis imaging: beyond annexin V. J Nucl Med. 2010;51(11):1659-62.

174. Hueting R, Tavare R, Dilworth JR, Mullen GE. Copper-64 radiolabelling of the $\mathrm{C} 2 \mathrm{~A}$ domain of synaptotagmin $\mathrm{I}$ using a functionalised bis(thiosemicarbazone): A pre- and post-labelling comparison. J Inorg Biochem. 2013;128:108-11.

175. Scabini M, Stellari F, Cappella P, Rizzitano S, Texido G, Pesenti E. In vivo imaging of early stage apoptosis by measuring real-time caspase-3/7 activation. Apoptosis. 2011;16(2):198-207.

176. Yang Q, Cui H, Cai S, Yang X, Forrest ML. In vivo photoacoustic imaging of chemotherapy-induced apoptosis in squamous cell carcinoma using a near-infrared caspase-9 probe. J Biomed Opt. 2011;16(11):116026.

177. Bauer C, Bauder-Wuest U, Mier W, Haberkorn U, Eisenhut M. 131I-labeled peptides as caspase substrates for apoptosis imaging. J Nucl Med. 2005;46(6):1066-74.

178. Nguyen QD, Challapalli A, Smith G, Fortt R, Aboagye EO. Imaging apoptosis with positron emission tomography: 'bench to bedside' development of the caspase- $3 / 7$ specific radiotracer [18F]ICMT-11. Eur J Cancer. 2012;48(4):432-40.

179. Challapalli A, Kenny LM, Hallett WA, et al. 18F-ICMT-11, a caspase-3-specific PET tracer for apoptosis: biodistribution and radiation dosimetry. J Nucl Med. 2013;54(9):1551-6.

180. Kim DY, Kim HS, Le UN, et al. Evaluation of a mitochondrial voltage sensor, (18F-fluoropentyl)triphenylphosphonium cation, in a rat myocardial infarction model. J Nucl Med. 2012;53(11):1779_ 85.

181. Madar I, Huang Y, Ravert H, et al. Detection and quantification of the evolution dynamics of apoptosis using the PET voltage sensor 18F-fluorobenzyl triphenyl phosphonium. J Nucl Med. 2009;50(5): 774-80.

182. Oborski MJ, Laymon CM, Lieberman FS, Drappatz J, Hamilton RL, Mountz JM. First use of 18F-labeled ML-10 PET to assess apoptosis change in a newly diagnosed glioblastoma multiforme patient before and early after therapy. Brain Behav. 2014;4(2): $312-5$. 
183. Dewkar GK, Sundaresan G, Lamichhane N, et al. Microfluidic radiosynthesis and biodistribution of [18F]2-(5-fluoro-pentyl)-2-methyl malonic acid. J Labelled Comp Radiopharm. 2013;56(5):289-94.

184. Grimberg H, Levin G, Shirvan A, et al. Monitoring of tumor response to chemotherapy in vivo by a novel small-molecule detector of apoptosis. Apoptosis. 2009;14(3):257-67.

185. Charles-Edwards EM, de Souza NM. Diffusion-weighted magnetic resonance imaging and its application to cancer. Cancer Imaging. 2006;6:135-43.

186. Gallagher FA, Kettunen MI, Hu DE, et al. Production of hyperpolarized [1,4-13C2] malate from [1,4-13C2] fumarate is a marker of cell necrosis and treatment response in tumors. Proc Natl Acad Sci U S A. 2009;106(47):19801-6.

187. Pisanu ME, Ricci A, Paris L, et al. Monitoring response to cytostatic cisplatin in a HER2 $(+)$ ovary cancer model by MRI and in vitro and in vivo MR spectroscopy. Br J Cancer. 2014;110(3):625-35.

188. Li X, Jiang H, Niu J, Zheng Y. Correlation of ADC value with pathologic indexes in colorectal tumor homografts in Balb/c mouse. Chin J Cancer Res. 2014;26(4):444-50.

189. Mignion L, Dutta P, Martinez GV, Foroutan P, Gillies RJ, Jordan BF. Monitoring chemotherapeutic response by hyperpolarized 13Cfumarate MRS and diffusion MRI. Cancer Res. 2014;74(3):686-94.

190. Foroutan P, Kreahling JM, Morse DL, et al. Diffusion MRI and novel texture analysis in osteosarcoma xenotransplants predicts response to anti-checkpoint therapy. PLoS One. 2013;8(12):e82875.

191. Jacobson O, Chen X. Interrogating tumor metabolism and tumor microenvironments using molecular positron emission tomography imaging Theranostic approaches to improve therapeutics. Pharmacol Rev. 2013;65(4):1214-56.

192. Rizzo LY, Theek B, Storm G, Kiessling F, Lammers T. Recent progress in nanomedicine: therapeutic, diagnostic and theranostic applications. Curr Opin Biotechnol. 2013;24(6):1159-66.

193. Terreno E, Uggeri F, Aime S. Image guided therapy: the advent of theranostic agents. J Control Release. 2012;161(2):328-37.

194. Chin PT, Welling MM, Meskers SC, Valdes Olmos RA, Tanke H, van Leeuwen FW. Optical imaging as an expansion of nuclear medicine: cerenkov-based luminescence vs fluorescence-based luminescence. Eur J Nucl Med Mol Imaging. 2013;40(8):1283-91.

195. van Leeuwen FW, de Jong M; EANM Translational Molecular Imaging Committee. Molecular imaging: the emerging role of optical imaging in nuclear medicine. Eur J Nucl Med Mol Imaging. 2014;41(11):2150-3.

196. van den Berg NS, Valdes-Olmos RA, van der Poel HG, van Leeuwen FW. Sentinel lymph node biopsy for prostate cancer: a hybrid approach. J Nucl Med. 2013;54(4):493-6.

197. Hildebrandt IJ, Su H, Weber WA. Anesthesia and other considerations for in vivo imaging of small animals. ILAR J. 2008;49(1):17-26.

198. Kersemans V, Cornelissen B, Hueting R, et al. Hypoxia imaging using PET and SPECT: the effects of anesthetic and carrier gas on [Cu]-ATSM, [Tc]-HL91 and [F]-FMISO tumor hypoxia accumulation. PLoS One. 2011;6(11):e25911.

199. Mullin L, Gessner R, Kwan J, Kaya M, Borden MA, Dayton PA. Effect of anesthesia carrier gas on in vivo circulation times of ultrasound microbubble contrast agents in rats. Contrast Media Mol Imaging. 2011;6(3):126-31.

200. Itani M, Mattrey RF. The effect of inhaled gases on ultrasound contrast agent longevity in vivo. Mol Imaging Biol. 2012;14(1):40-6.

201. Wible Jr JH, Wojdyla JK, Bales GL, McMullen WN, Geiser EA, Buss DD. Inhaled gases affect the ultrasound contrast produced by Albunex in anesthetized dogs. J Am Soc Echocardiogr. 1996;9(4):442-51.

202. Funk T, Sun M, Hasegawa BH. Radiation dose estimate in small animal SPECT and PET. Med Phys. 2004;31(9):2680-6.

203. Kersemans V, Thompson J, Cornelissen B, et al. Micro-CT for anatomic referencing in PET and SPECT: radiation dose, biologic damage, and image quality. J Nucl Med. 2011;52(11):1827-33.
204. Willekens I, Buls N, Lahoutte T, et al. Evaluation of the radiation dose in micro-CT with optimization of the scan protocol. Contrast Media Mol Imaging. 2010;5(4):201-7.

205. Delorme S, Knopp MV. Non-invasive vascular imaging: assessing tumour vascularity. Eur Radiol. 1998;8(4):517-27.

206. Madsen HH, Rasmussen F. Contrast-enhanced ultrasound in oncology. Cancer Imaging. 2011;11:S167-173.

207. Kiessling F, Razansky D, Alves F. Anatomical and microstructural imaging of angiogenesis. Eur J Nucl Med Mol Imaging. 2010;37 Suppl 1:S4-19.

208. Brix G, Griebel J, Kiessling F, Wenz F. Tracer kinetic modelling of tumour angiogenesis based on dynamic contrast-enhanced CT and MRI measurements. Eur J Nucl Med Mol Imaging. 2010;37 Suppl $1: \mathrm{S} 30-51$.

209. Buerkle A, Weber WA. Imaging of tumor glucose utilization with positron emission tomography. Cancer Metastasis Rev. 2008;27(4): 545-54.

210. McIntyre DJ, Madhu B, Lee SH, Griffiths JR. Magnetic resonance spectroscopy of cancer metabolism and response to therapy. Radiat Res. 2012;177(4):398-435.

211. Hurd RE, Yen YF, Chen A, Ardenkjaer-Larsen JH. Hyperpolarized 13C metabolic imaging using dissolution dynamic nuclear polarization. J Magn Reson Imaging. 2012;36(6):1314-28.

212. Debergh I, Van Damme N, De Naeyer D, et al. Molecular imaging of tumor-associated angiogenesis using a novel magnetic resonance imaging contrast agent targeting $\alpha v \beta 3$ integrin. Ann Surg Oncol. 2014;21(6):2097-104.

213. Xu QH, Shi JY, Zhang J, et al. Comparison of tumor neovasculature-targeted paramagnetic nanoliposomes for MRI in mice xenograft models. Clin Transl Oncol. 2014;16(4):395-401.

214. Dijkgraaf I, Beer AJ, Wester HJ. Application of RGD-containing peptides as imaging probes for alphavbeta3 expression. Front Biosci (Landmark Ed). 2009;14:887-99.

215. Gaertner FC, Schwaiger M, Beer AJ. Molecular imaging of $\alpha v \beta 3$ expression in cancer patients. Q J Nucl Med Mol Imaging. 2010;54(3):309-26.

216. Rylova SN, Barnucz E, Barnucz E, et al. Does imaging $\alpha v \beta 3$ integrin expression with PET detect changes in angiogenesis during bevacizumab therapy? J Nucl Med. 2014;55(11):1878-84.

217. Terry SY, Abiraj K, Frielink C, et al. Imaging integrin $\alpha v \beta 3$ on blood vessels with 111In-RGD2 in head and neck tumor xenografts. J Nucl Med. 2014;55(2):281-6.

218. Cai W, Chen X. Multimodality molecular imaging of tumor angiogenesis. J Nucl Med. 2008;49 Suppl 2:113S-28S.

219. Leguerney I, Scoazec JY, Gadot N, et al. Molecular ultrasound imaging using contrast agents targeting endoglin, vascular endothelial growth factor receptor 2 and integrin. Ultrasound Med Biol. 2015;41(1):197-207.

220. Chen F, Zhang Y, Cai W. Molecular MRI of VEGFR-2 reveals intratumor and inter-tumor heterogeneity. Am J Nucl Med Mol Imaging. 2013;3(4):312-6.

221. Sole CV, Calvo FA, Alvarez E, et al. Clinical significance of VEGFR-2 and 18F-FDG PET/CT SUVmax pretreatment score in predicting the long-term outcome of patients with locally advanced rectal cancer treated with neoadjuvant therapy. Eur J Nucl Med Mol Imaging. 2013;40(11):1635-44.

222. Levashova Z, Backer M, Hamby CV, Pizzonia J, Backer JM, Blankenberg FG. Molecular imaging of changes in the prevalence of vascular endothelial growth factor receptor in sunitinib-treated murine mammary tumors. J Nucl Med. 2010;51(6):959-66.

223. Nagengast WB, Hooge MN, van Straten EM, et al. VEGF-SPECT with 111 In-bevacizumab in stage III/IV melanoma patients. Eur J Cancer. 2011;47(10):1595-602.

224. van der Bilt AR, Terwisscha van Scheltinga AG, Timmer-Bosscha $\mathrm{H}$, et al. Measurement of tumor VEGF-A levels with $89 \mathrm{Zr}$ bevacizumab PET as an early biomarker for the antiangiogenic 
effect of everolimus treatment in an ovarian cancer xenograft model. Clin Cancer Res. 2012;18(22):6306-14.

225. Kuo F, Histed S, Xu B, et al. Immuno-PET imaging of tumor endothelial marker 8 (TEM8). Mol Pharm. 2014;11(11):39964006.

226. Quan Q, Yang M, Gao H, et al. Imaging tumor endothelial marker 8 using an $18 \mathrm{~F}$-labeled peptide. Eur J Nucl Med Mol Imaging. 2011;38(10):1806-15.

227. Knowles JA, Heath CH, Saini R, et al. Molecular targeting of ultrasonographic contrast agent for detection of head and neck squamous cell carcinoma. Arch Otolaryngol Head Neck Surg. 2012;138(7): 662-8.

228. Sugyo A, Tsuji AB, Sudo H, et al. Evaluation of 89Zr-labeled human anti-CD147 monoclonal antibody as a positron emission tomography probe in a mouse model of pancreatic cancer. PLoS One. 2013;8(4):e61230.
229. Correas JM, Helenon O, Pourcelot L, Moreau JF. Ultrasound contrast agents. Examples of blood pool agents. Acta Radiol Suppl. 1997;412:101-12.

230. Lutz AM, Bachawal SV, Drescher CW, Pysz MA, Willmann JK, Gambhir SS. Ultrasound molecular imaging in a human CD276 expression-modulated murine ovarian cancer model. Clin Cancer Res. 2014;20(5):1313-22.

231. Wang DL, Song YL, Zhu Z, et al. Selection of DNA aptamers against epidermal growth factor receptor with high affinity and specificity. Biochem Biophys Res Commun. 2014;453(4):681-5.

232. Foygel K, Wang H, Machtaler S, et al. Detection of pancreatic ductal adenocarcinoma in mice by ultrasound imaging of thymocyte differentiation antigen 1. Gastroenterology. 2013;145(4):885-894.e3.

233. Tsuruta JK, Klauber-DeMore N, Streeter J, et al. Ultrasound molecular imaging of secreted frizzled related protein-2 expression in murine angiosarcoma. PLoS One. 2014;9(1):e86642. 